\title{
¿Qué hace un micénico como tú en un sitio como éste? Andalucía entre el colapso de los palacios y la presencia semita
}

\author{
What's a mycenean boy like you doing in a place like this? Andalusia between the \\ Palaces' collapse and the coming of the Semites
}

Marisa Ruiz-Gálvez Priego (*)

\section{RESUMEN}

El trabajo revisa el contexto de las cerámicas micénicas a torno de Montoro y otros sitios andaluces, así como el contexto y la cronología de las primeras importaciones mediterráneas en la Península Ibérica, y plantea las coyunturas, técnicas, políticas y sociales que harían posible la existencia de rutas comerciales hacia los confines ibéricos. Asimismo, plantea el papel que pudo jugar la escritura alfabética en la aparición de un comercio privado entre fines del II milenio y los inicios del I milenio a.C. y su importancia en la llegada de productos mediterráneos a Occidente.

\begin{abstract}
The aim of the present paper is to rethink the finds of Mycenaean and other wheeled-made sherds at Late Bronze Age Andalusian sites, as well as the C14 chronology and archaeological context of the first Mediterranean imports in Iberia. It works also on the role that the alphabetic writing would have played in the appearance of private trade in the Mediterranean Late Bronze Age, and its connection with the first arrival of Mediterranean items in the West.
\end{abstract}

Palabras clave: Comercio mediterráneo; Comercio privado; Escritura; Autoconciencia; Micénicos; Koine; Comercio de un puerto a otro; Ponderales.

Key words: Mediterranean trade; Entrepreneurial trade; Writing abilities; Self-awareness; Mycenaeans; Koine; Tramping trade; Weight systems.

(*) Dpto. de Prehistoria. Facultad de Geografía e Historia. Universidad Complutense. E-28040 Madrid. Correo electrónico: marisar.gp@ghis.ucm.es

Recibido: 27-V-2009; aceptado: 2-IX-2009.

\section{INTRODUCCIÓN (1)}

Gracias a trabajos como los de Vagnetti y Jones (1988; Jones y Vagnetti 1991), es hoy un hecho aceptado que la presencia micénica en el Mediterráneo Central fue algo más que una esporádica frecuentación comercial e implicó la transferencia de tecnología, lo que sugiere el asentamiento de algunos individuos en el seno de la población indígena, aunque no pueda hablarse en sentido estricto de una colonización (Vagnetti 1993, 1998, 2000: 312; Bernardini 1991, 2008). De ahí que muchos investigadores hayan considerado factible la hipótesis de la extensión de dicho comercio hacia los confines de occidente, a partir de la cabeza de puente que representaría la Península Italiana y las islas del Tirreno (Martín de la Cruz 1994; Almagro 1993; Mederos 1999; Guerrero 2004: 105). Ya en los años 1970, Schubart (1976) señaló las peculiares características de las copas argáricas y su posible imitación de vajilla metálica, plausiblemente plata, de origen oriental. Pero es el hallazgo de diversos fragmentos de cerámica a torno en varios niveles del sitio cordobés de Montoro (Martín de la Cruz 1988), lo que supuso una llamada de atención y tuvo como consecuencia el reconocimiento de que no se trataba de un hecho único, sino que otras cerámicas a torno se habían recogido previamente en

(1) Trabajo realizado dentro del proyecto HUM20040437/Hist titulado "Héroes Mediterráneos: comercio, escritura y pensamiento abstracto". Este texto se escribió para el coloquio sobre "la Prehistoria Reciente en Andalucía Central" organizado en noviembre de 2004 por el Pr. Martín de la Cruz en la Universidad de Córdoba y se actualizó para su publicación en la revista Trabajos de Prehistoria. 
contextos de Bronce Tardío o Final indígena, aunque hasta entonces no se habían sabido interpretar (Arribas 1976; Pellicer y Amores 1985; Castro et al. 1993; Almagro y Fontes 1997). Las cerámicas a torno de Montoro permitieron, además, encajar en un marco cronológicamente comprensible otros hallazgos antiguos claramente mediterráneos pero no fenicios, habitualmente etiquetados como "precoloniales".

La intención de este trabajo es revisar desde el punto de vista, tanto de las potencias mercantiles del Mediterráneo Oriental como de las poblaciones indígenas peninsulares, los contextos no sólo cronológicos, sino sobre todo, políticos y tecnológicos, es decir, las "coyunturas" (2) en las que sería factible la existencia de una corriente comercial hacia la Península Ibérica. Ya en otros trabajos (Ruiz-Gálvez 1993, 1998a, 1998b, 2000a, 2000b, 2005a, 2005b, 2008) he reiterado mi creencia de que la colonización fenicia del I milenio a.C. (3) no fue fruto del azar, de "viajes exploratorios" o de una fase previa de comercio sin colonias, como seguramente tampoco lo fue la griega. Sino que, por el contrario, lo sistemático del asentamiento, el que desde el inicio se afinque a ambos lados del Estrecho y siempre solapándose a poblamiento indígena, o en la proximidad de núcleos indígenas que en los cien o ciento cincuenta años previos han conectado rutas locales con otras del Mediterráneo o del Atlántico, señala que los confines occidentales habían entrado ya a formar parte de las rutas mediterráneas en algún momento del II milenio a.C.

La cuestión es precisar desde cuándo: si desde inicios del II milenio y entonces en conexión con una naciente ruta micénica hacia el Mediterráneo Central u otra de origen aún más lejano; si desde 1400 a.C. y entonces, en conexión con la clara presencia micénica en el Tirreno; o si después del 1200 a.C. y por tanto, tras la Edad del Bronce del Mediterráneo Oriental y tras la desaparición de los principales protagonistas de las rutas comerciales del II milenio a.C. Determinar esto no es baladí, porque dependiendo de qué período cronológico estemos hablando, pueden existir argumentos que hagan plausible dicha hipótesis (como cambios en sistemas económicos o en coyunturas políticas, o

(2) En el sentido que la escuela francesa de los Annales usa esta palabra.

(3) Uso a.C. cuando me refiero a cronología histórica o tipológica y cal B.C. cuando uso dataciones C14 calibradas. innovaciones en las técnicas de transporte) o que, por el contrario, la hagan poco creíble.

\section{¿EN QUÉ CONTEXTO RESULTARÍA FACTIBLE LA INCLUSIÓN DEL MEDITERRÁNEO OCCIDENTAL EN LAS RUTAS DE LA EDAD DEL BRONCE?}

Aún a riesgo de resultar reiterativa, me reafirmo en la idea de que la Historia de las colonizaciones (Curtin 1984; Chandeigne (dir.) 1992; Keay 1993; Stein (ed.) 2005) nos enseña que, en condiciones de tecnología y transporte primitivos, la exploración de nuevas rutas supone un esfuerzo humano, técnico y económico muy considerables y que tal empresa responde menos a la curiosidad humana o al deseo de exploración, que a la unión de una serie de coyunturas que la hacen posible y, sobre todo, necesaria. Para expresarlo con una imagen comprensible: lo importante no es que, hipotéticamente, escandinavos, irlandeses o chinos pudieran haber llegado a América antes que los castellanos. Lo realmente importante fue que estos últimos fueran capaces de ir y volver, de dar a conocer la existencia de otro continente, de crear rutas regulares entre ambos extremos del océano y de asentarse en número significativo como para crear colonias en las tierras de América.

\section{SOBRE LA FINALIDAD DEL COMERCIO EN EL MUNDO ANTIGUO}

El comercio a larga distancia cumplía una importante serie de funciones en los Estados del II milenio a.C. (Liverani 2003: 199 y ss).

$-1 .^{\circ}$ Complementar recursos en áreas ecológicas diversas del amplio territorio bajo control estatal. Esto podría haberse llevado a cabo mediante rutas internas.

-2 . $^{\circ}$ Proporcionar materia prima para la guerra y la conquista. Éste es el destino principal del metal. La conquista o la subordinación a su vez aseguran el control de nuevas fuentes de materias primas, mano de obra esclava y el pago de tributo.

-3 . $^{\circ}$ Proveer de materias primas o mercancías exóticas de valor categorizador que en sociedades analfabetas, basadas en la apariencia visual, adquieren un papel básico en la definición del poder y del origen del cual éste emana. Es decir, en la propaganda política. Materias como el 
incienso, el oro o la púrpura, de alto valor emblemático, entrarían en este capítulo.

$-4 .^{\circ}$ En el sentido del apartado anterior, proporcionar instrumentos para el juego de las alianzas. Mercancías o manufacturas exóticas, costosas o escasas que forman parte del tributo por el que un dinasta menor reconoce su sometimiento a un imperio mayor o más poderoso, o del regalo que precede o sustituye las alianzas matrimoniales entre reyes de igual o desigual rango y que forman parte del juego del dominio universal. Pues, en palabras de Gregory (1982: 10-19), se trataría de "objetos inalienables intercambiados entre no extraños". A su vez, ello provocaría un fenómeno de emulación en el que dignatarios de mayor o menor rango reproducirían a escala menor el juego de las alianzas, tratando de acceder para ello a mercancías o manufacturas que imitaban o se asemejaban a aquellas monopolizadas por los individuos de rango regio y a formas de consumo asimismo categorizadoras.

Así, los objetos dejarían de ser neutros para, bien al contrario, codificar un lenguaje acerca del poder y del papel que cada individuo juega dentro de su sociedad. La condición para ello sería que el acceso al consumo de tales objetos codificadores quedara rígidamente limitado, pues, de lo contrario, perdería su valor categorizador. Así, hoy un abrigo de piel de armiño puede significar moda y dinero -aunque no necesariamente (4) pero ya no lo que hubiera significado en el Antiguo Régimen: signo de pureza y por extensión de la realeza por mandato divino. Por ello, era monopolio de reyes y emperadores. Otro tanto podría decirse del jade blanco o de la seda amarilla, monopolio de los emperadores chinos.

Las evidencias, tanto arqueológicas como textuales de talleres artesanales dependientes de los palacios mediterráneos del II milenio a.C., permiten pensar en el carácter de artesanos a tiempo total de quienes laboraban en ellos. Como ya explicaron en su día Brumfiel y Earle (1987: 5), la especialización a tiempo total es sólo factible cuando es posible asegurar tanto una amplia demanda como un flujo estable, constante de materias primas. Eso, en condiciones de transporte primitivo, supone buscar constantemente nuevas fuentes de aprovisionamiento como alternativa a posibles imprevistos en las habituales.

(4) Los grandes almacenes ofrecen múltiples fórmulas para el pago aplazado.

\section{POSIBLES ÁREAS \\ DE ABASTECIMIENTO \\ DE MATERIAS PRIMAS}

Entre fines del III milenio a.C. e inicios del II milenio a.C. las rutas comerciales del Próximo Oriente se extendieron hacia Anatolia, la Tróade y el Egeo para acceder a materias primas de las áreas periféricas como cobre, plata, oro, obsidiana, mármol, maderas preciadas (Manning 1994). A comienzos del II milenio a.C. el cobre, oro, estaño y ámbar de las áreas de los Balcanes y los Cárpatos y, a través de éstas, del Centro Norte de Europa convierten a aquellas en periferia del mundo micénico a través de lo que conocemos como "ruta del ámbar" (Sherratt 1993). A partir del siglo XVI a.C. las rutas se extienden hacia el Mediterráneo Central (Vagnetti 1993) y ello produce una reorientación hacia el oeste, hacia los recursos mineros del área alpina, de dicha "ruta del ámbar" (Sherratt 1993: Fig. 9). No es casualidad que los túmulos más ricos del Bronce Nórdico se concentren entre 1400-1300/1250 a.C. de acuerdo con la dendrocronología (Christensen 1998: 110-113). Entre ellos, el de Guldhøj, que contenía una silla plegable de madera de modelo egipcio/egeo (Jensen 1998: 108), o la tumba de Kivit en el Sudeste de Suecia (Randsborg 1993, 1998; Larsson 1999), datada ca. 1300 a.C., cuyos ortostatos contienen grabados de tipo mitológico y claro sabor oriental, destacando la representación de un varón sobre un carro de dos ruedas radiales, que reproduce exactamente la iconografía del faraón que se generaliza como símbolo del poder en el Mediterráneo a partir del siglo XVI a.C. (Knapp 1998).

De esta iconografía egipcia deriva igualmente la representación micénica y, en última instancia, de ésta, la escandinava (Lám. I). Otros elementos de posible origen mediterráneo son las representaciones de barcos, tanto en Kivit y otras tumbas escandinavas, como en el arte al aire libre que, según Larsson (1998: 14-15) indican conexiones con el mundo mediterráneo-micénico. En efecto, a mi juicio, los barcos representados en el arte rupestre escandinavo no reproducen embarcaciones locales de cuero ni de madera, sino una iconografía mediterránea, la de un tipo de barco con galería de remeros, tipo pentecontera, que se generaliza en el Mediterráneo Oriental entre 1300-1200 $\mathrm{BC}$, es decir, muy a fines de la Edad del Bronce y que aparece pintado en cerámicas del HRIIIB y 


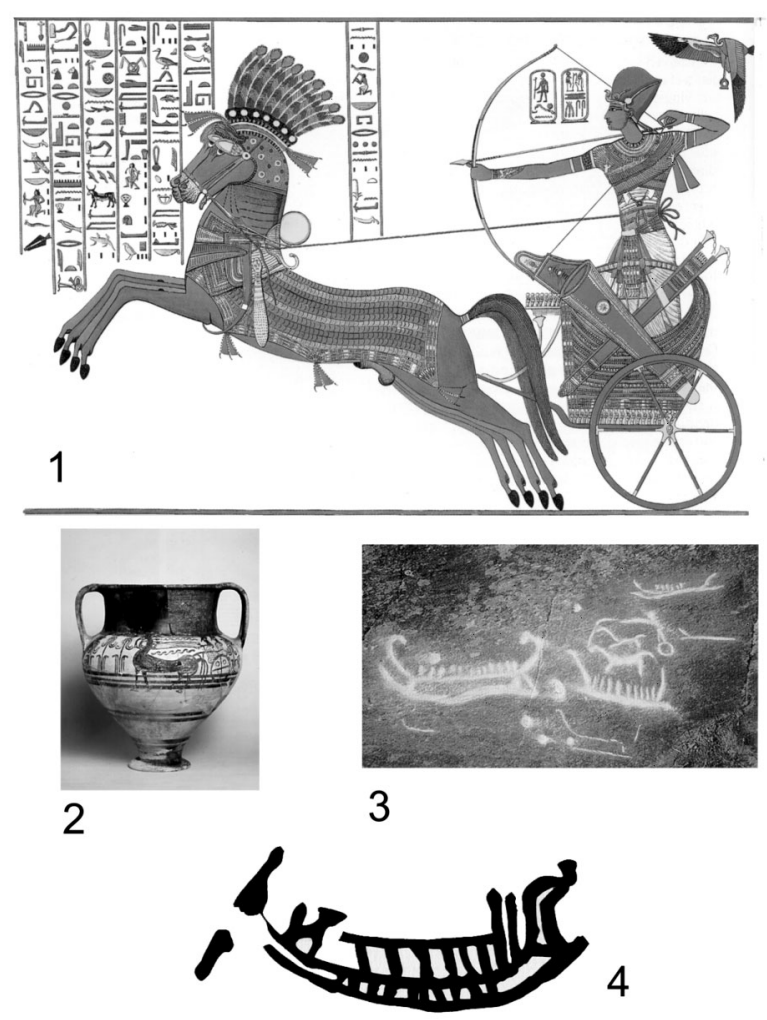

Lám. I. Comparación entre la iconografía mediterránea y el arte escandinavo al aire libre. 1. Ramsés II en la batalla de Qadesh. 2. Crátera anforoide del HRIIIB de Nafpio (según Melena [ed.] 1992). 3. Grabados de carros y barcos en un petroglifo sueco (foto del Gotland University College, Suecia). 4. Calco de un barco pintado en una urna funeraria de Hama (Siria) ca. 1200-1075 a.C.) (según Waschmann 1997, fig. 27).

HRIIIC, así como en otros soportes (Waschmann 1997, 1998).

Naturalmente no estoy sugiriendo la existencia de una ruta entre el Mediterráneo y el Báltico ni, mucho menos, la presencia regular o esporádica de comerciantes micénicos. Lo que sí planteo es que esa ruta down the line, fue lo suficientemente fluida y continuada como para que, en forma de pinturas, tejidos, o cualquier otro soporte, llegara hasta los confines de Europa la imagen de cómo se representaba el poder en el mundo mediterráneo y creara fenómenos de emulación (Lám. II) (5).

(5) Como el ejemplo que se muestra en la lámina II. Corresponde a una representación de los portugueses en el patio principal del palacio de Udaipur (India) del siglo XVII a.C. Los

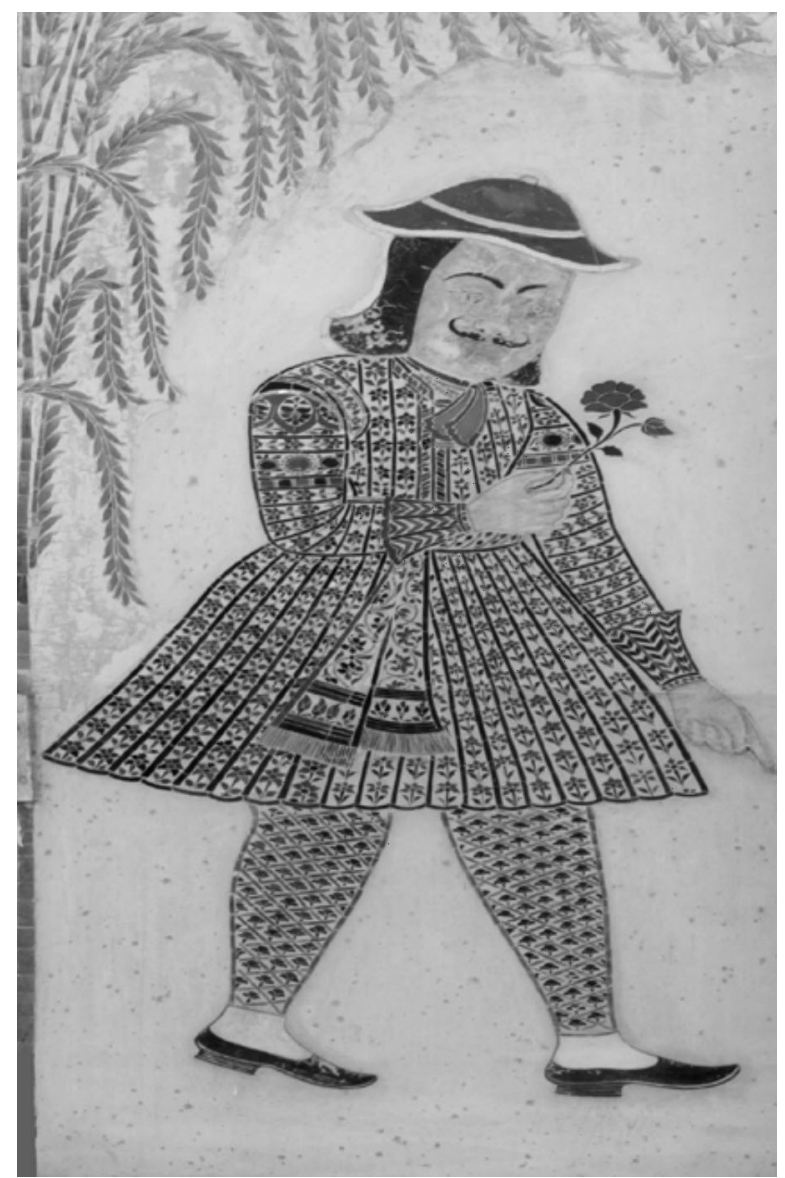

Lám. II. Un ejemplo de fenómeno de emulación la "representación" de un portugués en el patio del siglo XVII del palacio de Udaipur (Rajastán, India) (foto: Eugenio Ruiz-Gálvez Priego).

Lo que, a mi juicio, representa la "ruta del ámbar" es la creación de un área de intercambio común, que utiliza el mismo sistema de peso estándar para sus transacciones externas, que es mediterráneo y que corresponde al de la ruta comercial dominante en esos momentos, esto es a la unidad egea de 65/68 g (Petruso 1978; Parise 1986). Pues, en efecto, la unidad egea aparece a lo largo de toda la ruta: en la Península Itálica, donde Peroni (1998), la identifica en contextos de Bronzo Reciente (siglo XIII a.C.), en Centroeuropa a partir de fechas similares (Eiwenger 1989) y, por último, en Escandinavia. En este último pun-

portugueses nunca se establecieron en el Rajastán, sino más al sur, en Bomba Goa, pero sí mandaron embajadas a algunos de los principales reinos como el de Udaipur, que aunque no fructificaron en tratados comerciales sí tuvo un fuerte impacto simbólico propagandístico. 
to, Malmer $(1992,1999)$ razonando que, puesto que todo el metal empleado en Escandinavia en la Edad del Bronce era de procedencia foránea, debía responder a una unidad de peso también foránea, identificó la existencia de concentraciones de peso significativas en armas, torques y estatuillas de bronce y oro escandinavos. Aunque no identificó a qué unidad de peso correspondía, el autor especuló con su posible origen mediterráneo. Ulteriormente la autora (Ruiz-Gálvez 1998a, 2000a) identifica dicha unidad como el siclo egeo de 6,5/6,8 g, fracción de la unidad de 65/68 g atestiguada en los registros de Ebla (Zaccagnini 1986). Así, para usar una imagen comprensible para el lector moderno, nos encontraríamos con un amplio territorio en el que la unidad egea habría sido universal para las transacciones externas, al igual que hoy en buena parte de Asia hablamos del "área yen", en Europa del "área euro", en buena parte del mundo del "área dólar", reflejando con ello las principales áreas económicas en las que unas y otras divisas se utilizan como elemento internacional de referencia para las transacciones.

Recapitulando, lo que he tratado de plantear hasta ahora es cómo a lo largo del II milenio a.C. las rutas comerciales del Mediterráneo se van ampliando, y cómo es posible detectar dichas rutas a través de evidencias directas de comercio, o indirectas de incorporación de aspectos del mundo mediterráneo a la iconografía o a la simbología de sociedades indígenas periféricas.

\section{¿QUÉ DATOS POSEEMOS DE UNA POSIBLE PRESENCIA DIRECTA O INDIRECTA DE COMERCIO MEDITERRÁNEO HACIA LA PENÍNSULA IBÉRICA?}

Vaya por delante mi creencia de que, desde los inicios del Holoceno, el Mediterráneo fue la vía de comunicación preferente y más económica de los pueblos costeros. Naturalmente, me refiero a pequeños desplazamientos que, seguramente hasta la Edad del Bronce, tienen como función la pesca y la comunicación más que el intercambio. A partir de la Edad del Bronce empezamos a tener mayores evidencias de rutas eminentemente comerciales, que por la dispersión de hallazgos parecen haberse realizado sobre la base del pequeño o gran cabotaje $y$, por tanto, sin alejarse en exceso de tierra firme y acostando al anochecer. Sólo a partir de fechas muy concretas (siglos XIV-XIII a.C.), comenzamos a tener evidencias de innovaciones en construcción naval o de uso de faros y de iluminación nocturna y con ello, de navegación de altura. Sólo entre el siglo XIII y el XII a.C. (HRIIIB/IIIC) aparecen representados barcos versátiles tipo pentecontera, con capacidad de carga y con autonomía para navegar aún sin viento, que hacen factible pensar en rutas a larga distancia que permitieran alcanzar la Península Ibérica (Ruiz-Gálvez 2005b).

Antes de esas fechas, que corresponden a las fases finales de los palacios y al tránsito a la Edad del Hierro en el Mediterráneo Oriental, me parece difícil aceptar una navegación directa desde el Mediterráneo Central hasta la Península, ni siquiera a través del puente entre las islas del Tirreno, las Baleares. Como explica Guerrero (2004), entre el centro del Mediterráneo y las Baleares no es posible navegar guiándose a partir del avistamiento de tierra firme. Todo ello, a falta de orientación nocturna y de barcos con autonomía que permitieran la navegación de altura y con suficiente capacidad de carga para sostener una tripulación y para transportar mercancía suficiente como para compensar el largo recorrido, invalida la hipótesis de una ruta directa entre las islas del Mediterráneo Central y los confines ibéricos. La única ruta plausible sería la de cabotaje a través de la desembocadura del Ródano y Golfo de León hacia la costa levantina ibérica (Guerrero 2004), hecho que invitaría más a pensar en rutas indirectas a través de intercambios entre los indígenas, que en comunicación directa entre comerciantes mediterráneos y la Península Ibérica. Sería algo, en cierta medida, similar a la relación entre el mundo escandinavo y el mediterráneo que veíamos antes. Sin embargo, hay pocos hallazgos de tipo micénico o, en general mediterráneo, en la costa francesa hasta época posmicénica (6). Esto y la ausencia en Córcega de indicios, directos o indirectos, de comercio micénico, cuando sí los hay en lo que más tarde será la Etruria (Vagnetti 1993), son dos hechos que no parecen aleatorios, sino que seguramente reflejan una realidad: que se trata de áreas de escasos recursos o de bajo interés comercial para los traficantes mediterráneos. Luego, en mi opinión, antes del siglo XIV o del XIII a.C., no se dan las condiciones para la

(6) Guilaine y Verguer (2008: 222-223) publican una espada de tipo micénico dragada en Sète (Languédoc) un lingote de tipo chipriota procedente de Sant'Anastasia, Córcega, aunque no especifican el contexto de hallazgo de este último. 
extensión del comercio mediterráneo hacia la Península Ibérica. Con anterioridad pudo haber algún contacto lejano y esporádico, porque desde la Edad del Bronce, Europa estuvo comunicada entre sí directa o indirectamente. Lo que no creo, insisto, es en un tráfico lo suficientemente continuado como para haber dejado evidencias abundantes como en el caso de Italia, o para haber creado procesos de emulación o haber sido incorporado al imaginario mítico, como en Escandinavia.

\section{¿QUÉ FIABILIDAD POSEEN ESAS EVIDENCIAS DE TRÁFICO MEDITERRÁNEO PREFENICIO?}

En 1976, Schubart señaló las semejanzas de las copas argáricas con el servicio para la bebida en plata mediterráneo. Él planteaba (Schubart 1976: 342), no tanto movimientos comerciales continuados o de larga duración, como viajes esporádicos que, vistas las fechas radiocarbónicas que sitúan el final de El Argar no más tarde del 1500 B.C. (Castro et al. 1996), me cuesta mucho admitir, por las razones antes comentadas. Sí creo que el Mediterráneo es un mundo abierto y que es más fácil comunicarse por esa vía que por caminos interiores, de la misma manera que creo que el proceso de neolitización del Mediterráneo tuvo más que ver con un modelo de "capilaridad" (Rodríguez Alcaide et al. 1996), que con otros puros o duales de migración (Bernabeu et al. 1993). Por eso, sí me parecen aceptables algunas ideas del mencionado trabajo de Schubart, es decir, que en una cadena continuada de relaciones constituida por pequeñas navegaciones indirectas, lo que estén reflejando las copas argáricas sea la generalización en la cuenca mediterránea del concepto de la bebida (7), el contexto ritual en que ésta era consumida y la vajilla especial en la que se servía. Aunque no creo, naturalmente, en contactos directos con egipcios, hititas o micénicos.

Otros hallazgos orientales en la Península Ibérica usados para argumentar la existencia de rutas de navegación en época muy temprana son, a mi juicio, igualmente problemáticos a causa tanto de su cronología, como de sus orígenes variopintos: anatólicos, egipcios o egeos. $\mathrm{O}$, como en el caso de un cilindro sello sirio y un collar de pasta ví-

(7) Fuera vino u otra bebida alcohólica para la que las copas argáricas estuvieran destinadas. trea y ámbar encontrados en Vélez Málaga hacia 1870 (Martín de la Cruz 1994, 2008: 291), porque desconocemos el contexto y circunstancias del hallazgo, si es que de verdad procedían de un hallazgo arqueológico y no del tráfico de antigüedades. Como ya señalé en otro lugar (Ruiz-Gálvez 2005a: 265 y ss), no cabe descartar que aparecieran en contextos fenicios, pues la presencia de "antigüedades", bien procedentes del expolio de tumbas, bien como parte de la "invención" de unos orígenes aristocráticos por parte de nuevas clases mercantiles emergentes, no es infrecuente en tumbas heroicas de época submicénica y geométrica griega o en las de poderosas familias fenicias de inicios del I milenio a.C. (Ruiz-Gálvez 2005a: 267). En idéntico sentido, el contexto del colgante de cornalina de la provincia de Córdoba, para el que se sugiere una cronología del HRIIIB y origen egipcio o, cuando menos, oriental, pero de cuya asociación arqueológica no se nos informa, me obliga a mantener cierta cautela (Martín de la Cruz et al. 2005: 503 y ss.; ver también Escacena 2008: 313).

Otras evidencias, sin embargo, pueden ser más sólidas. A raíz de los trabajos del Pr. Martín de la Cruz (1988) en el Llanete de los Moros de Montoro, se puso en evidencia la presencia de cerámica a torno en contextos indígenas del sur de la Península y permitió valorar el significado de otros fragmentos de cerámica a torno en idénticos contextos indígenas de alta cronología. Tal fue el caso de los fragmentos de un soporte y un contenedor hallados en el interior de una cabaña de adobe del poblado del "Bronce Tardío" o postargárico (8) de Purullena (Granada), asociados a cerámicas tipo 'Boquique' y algunas excisas. Dos dataciones, la primera (GrN-7284) obtenida sobre trigo carbonizado del interior del contenedor y, por tanto, muy fiable, y la segunda (GrN-7825) de carbón procedente de un nivel de incendio de una casa del "Bronce Tardío" (Arribas 1976: nota 36), ofrecen unos contextos muy altos que nos situarían al menos, en fechas de entre los siglos XV-XIII cal B.C. (véanse Fig. 1 y Tab. 1). En cuanto al posible origen de ambos recipientes nada se sabe, pero los análisis por activación neutrónica indican que proceden del mismo taller en el que se fabricaron otros a torno no decorados, descubiertos en el citado yacimiento cordobés de Llanete de los Moros (Martín de la Cruz 1994).

(8) Por tanto, después de 1500 B.C. (Castro et al. 1996). 


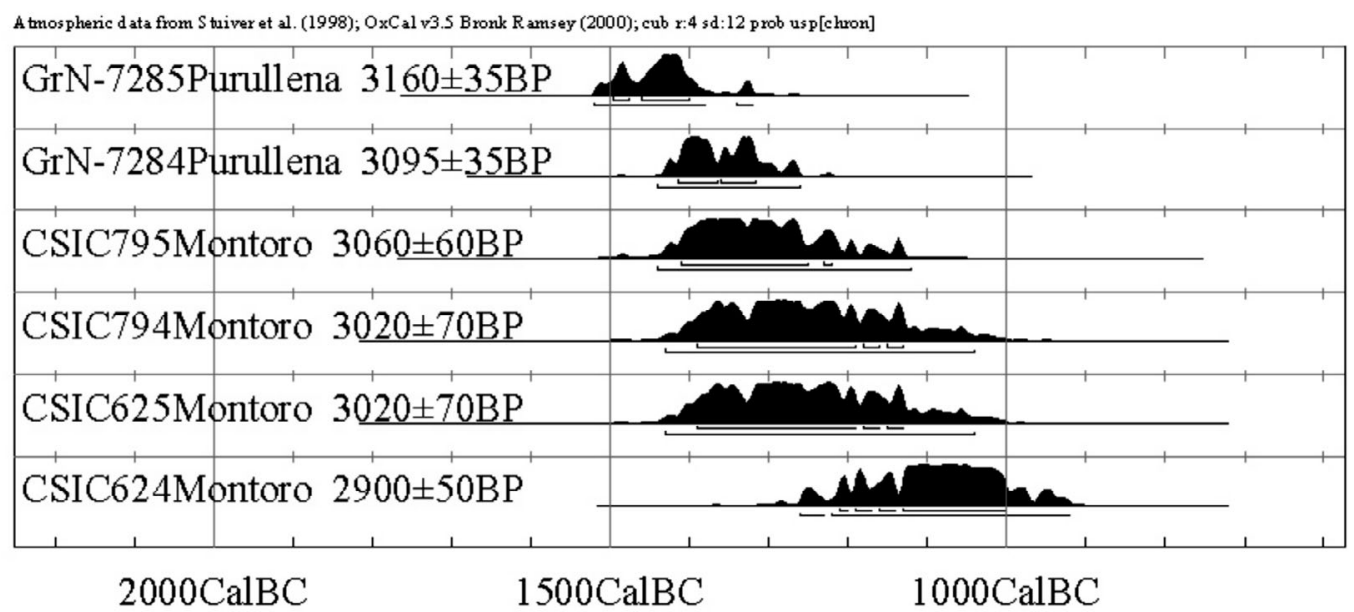

Fig. 1. Dataciones C14 calibradas de los contextos en que aparecen cerámicas a torno en la Cuesta del Negro (Purullena, Granada) y el Llanete de los Moros (Montoro, Córdoba).

Es éste un asentamiento que controla la salida de Sierra Morena desde el puerto de El Rey y el cruce del vado del Guadalquivir medio (Uriol 1990). Sus materiales, Boquique y excisión, permiten situarlo en contextos de "Bronce Tardío". Pero lo que hizo internacionalmente conocido el sitio, fue el hallazgo de dos pequeñísimos fragmentos de cerámica a torno (Martín de la Cruz 1988). Que se trata de cerámica micénica parece indudable y su análisis por activación neutrónica señala que proceden del taller Micenas-Berbati en la Argólida (Martín de la Cruz y Perlines 1993: 335 y ss; Perlines 2005: 483). En cuanto a su cronología, tradicionalmente situada entre los siglos XIV-XIII a.C., se basa, a mi juicio, en un argumento circular. Podzuweit (1990), quien estudió ambos fragmentos, señala la dificultad que entraña su identificación por lo extremadamente pequeño del tamaño de ambos. Respecto al fragmento de pie, según Podzuweit (1990: 53), por la calidad de la pasta y del tratamiento de la superficie, podría corresponder a cerámicas del HRIIIA/IIIB, pero que la dificultad de reconstruir la forma concreta a la que pertenece impide una cronología precisa. El autor considera que su cronología debe ser anterior a fines del HRIIIB o al HRIIIC, porque en esos momento es poco frecuente que los pies de copas aparezcan pintados por dentro y por fuera (Podzuweit 1990: 53), pero tampoco se atreve a definirse sobre forma y cronología. Apenas apunta que puede ser una forma abierta y tratarse de un cráter con asas en ángulo recto y pie cónico, y entonces se dataría en el HRIIIA1/B2; o de una forma cerrada, y entonces su datación sería del
HRII (Podzuweit 1990: 54). Más dificultosa aún es la identificación del segundo fragmento, que lleva una ancha banda de pintura oscura en la superficie externa y es de buena calidad. Podzuweit (1990: 55) especula sobre si podría tratarse de una taza o cubilete y entonces tendría una cronología del HRIIA2-IIIA, o de un cuenco, y entonces se dataría en el HRIIIB. La definitiva adscripción cronológica parece estar determinada más porque el autor (Podzuweit 1990: 56) sigue la cronología de Schubart para la fase Cogotas I o postargárica (siglo XIII a.C.), a la que corresponde el contexto indígena en que aparecieron estas cerámicas micénicas -lo que es un argumento circular-y porque las cerámicas del HRIIIC tienen, por lo general, un tratamiento de superficie peor y suelen ser de fabricación local, que porque haya criterios seguros y objetivos de identificación de los fragmentos de cerámica micénica. El contexto arqueológico al que se asocian, tampoco permite precisiones. En concreto, del nivel al que pertenecen los fragmentos de cerámica micénica procede una datación sobre carbón de CSIC-795, corroborada por otra datación del nivel superior, por tanto más reciente, de CSIC-794. Una tercera datación, asociada a cerámicas a torno similares a las de Purullena y a otras indígenas tipo Cogotas I es CSIC-624 (9) (véanse Fig. 1 y Tab. 1). Las tres, en conjunto, marcan un lapso de tiempo muy amplio que puede ir, en términos de cronología

(9) Otras dos dataciones asociadas a estas cerámicas a torno son escasamente útiles por su alta desviación estándar de 110 y 130 años. 


\begin{tabular}{|c|c|c|c|c|}
\hline Sigla & $\begin{array}{l}\text { Número } \\
\text { Muestra }\end{array}$ & Procedencia & Fecha BP & $\begin{array}{c}\text { Fecha cal } \\
\text { BC } 2 \sigma\end{array}$ \\
\hline $\mathrm{GrN}$ & 7285 & Purullena & $3160 \pm 35$ & $1510-1320$ \\
\hline GrN & 7284 & Purullena & $3095 \pm 35$ & $1440-1260$ \\
\hline CSIC & 795 & Montoro & $3060 \pm 60$ & $1450-1120$ \\
\hline CSIC & 794 & Montoro & $3020 \pm 70$ & $1430-1050$ \\
\hline CSIC & 625 & Montoro & $3020 \pm 70$ & $1430-1050$ \\
\hline CSIC & 624 & Montoro & $2900 \pm 50$ & $1260-930$ \\
\hline SAC & 1539 & Outerio de Beijós* & $2960 \pm 45$ & $1370-1020$ \\
\hline SAC & 1566 & Outerio de Beijós* & $2930 \pm 60$ & $1320-930$ \\
\hline SAC & 1524 & Outerio de Beijós* & $2610 \pm 60$ & $910-540$ \\
\hline ICEN & 834 & Moreirinha & $2940 \pm 45$ & $1300-1000$ \\
\hline ICEN & 835 & Moreirinha* & $2910 \pm 45$ & $1270-970$ \\
\hline GrN & 19669 & Moreirinha & $2785 \pm 15$ & $1010-890$ \\
\hline OXA & 4085 & Moreirinha & $2780 \pm 70$ & $1270-970$ \\
\hline ICEN & 969 & Monte do Frade* & $2920 \pm 50$ & $1300-970$ \\
\hline ICEN & 971 & Monte do Frade* & $2850 \pm 45$ & $1200-900$ \\
\hline GrN & 19660 & Monte do Frade* & $2805 \pm 15$ & $1005-910$ \\
\hline ICEN & 970 & Monte do Frade & $2780 \pm 100$ & $1260-790$ \\
\hline CSIC & 202 & Ría de Huelva & $2830 \pm 70$ & $1210-820$ \\
\hline CSIC & 203 & Ría de Huelva & $2820 \pm 70$ & $1210-820$ \\
\hline CSIC & 206 & Ría de Huelva & $2820 \pm 70$ & $1210-820$ \\
\hline CSIC & 207 & Ría de Huelva & $2820 \pm 70$ & $1210-820$ \\
\hline CSIC & 205 & Ría de Huelva & $2810 \pm 70$ & $1210-810$ \\
\hline CSIC & 204 & Ría de Huelva & $2800 \pm 70$ & $1130-800$ \\
\hline GrN & 7484 & Baiòes & $2650 \pm 130$ & $1150-400$ \\
\hline CSIC & 360 & Peña Negra 1 & $2690 \pm 50$ & $970-790$ \\
\hline CSIC & 484 & Peña Negra 1 & $2670 \pm 50$ & $930-770$ \\
\hline CSIC & 410 & Peña Negra 1 & $2580 \pm 50$ & $840-530$ \\
\hline CSIC & 392 & Peña Negra II & $2570 \pm 50$ & $830-530$ \\
\hline UBAR & 347 & Convento Franciscano & $2690 \pm 50$ & $970-790$ \\
\hline UGRA & 551 & Pocito Chico & $3350 \pm 80$ & $1880-1450$ \\
\hline UGRA & 550 & Pocito Chico & $2540 \pm 100$ & $850-400$ \\
\hline UGRA & 549 & Pocito Chico & $2340 \pm 100$ & $800-150$ \\
\hline SAC & 1524 & Outerio de Beijós* & $2610 \pm 60$ & $910-540$ \\
\hline CSIC & 1096 & São Julião* & $2789 \pm 42$ & $1050-830$ \\
\hline ICEN & 1277 & São Julião* & $2780 \pm 50$ & $1050-810$ \\
\hline ICEN & 1280 & São Julião* & $2760 \pm 70$ & $1090-790$ \\
\hline ICEN & 829 & São Julião* & $2660 \pm 45$ & $910-780$ \\
\hline CSIC & 1184 & São Julião* & $2548 \pm 22$ & $800-560$ \\
\hline GrN & 13706 & Torroso II & $2555 \pm 30$ & $810-550$ \\
\hline GrN & 19052 & Soto IX & $2675 \pm 35$ & $900-790$ \\
\hline GrN & 19053 & Soto XI & $2640 \pm 50$ & $920-660$ \\
\hline GrN & 19055 & Soto IV & $2620 \pm 50$ & $910-560$ \\
\hline
\end{tabular}

Tab. 1. Cuadro de dataciones radiocarbónicas de objetos mediterráneos procedentes de excavaciones arqueológicas recientes en yacimientos del Bronce Final en la Península Ibérica. Programa de calibración Oxcal. 3.10. En la columna izquierda, aparece la sigla del laboratorio; * presencia de piezas de hierro.

heládica del HRII al IIIC/ Submicénico, por lo que no ayuda, al menos a mí, a situar claramente el contexto de estas cerámicas y el de las a torno no decoradas de Purullena. Estas últimas proceden del mismo taller que las a torno no decoradas de Montoro, pero presentan una cronología muy diferente (Fig. 1). Quiero insistir en el hecho de que la fecha sobre trigo de Purullena es muy fiable, no porque las otras fechas radiocarbónicas no lo sean, que lo son, sino porque la muestra datada es de vida corta y por tanto, al contrario que las obtenidas sobre madera o carbón, nos da un lapso de tiempo muy breve entre la siega y el consumo.
Así pues, cabe admitir que, siendo conservadores y aceptando el lapso cronológico más reciente para la muestra GrN-7284, estemos a mediados del siglo XIII a.C. Esta fecha sí me parecería aceptable por contexto histórico, por evidencias de cambio político y por evidencias de innovación tecnológica. Y me explico: $10^{\circ}$ porque, para esos momentos, la presencia de comercio sensu lato micénico es clara en el Tirreno; $2 .^{\circ}$ porque para esas fechas hay indicios de cambio en el sistema de comercio y de un papel activo de comerciantes privados, periféricos a los grandes Estados mediterráneos; $3 .^{\circ}$ porque para esas fechas hay buenas evidencias de innovaciones en tecnología naval que me permiten aceptar una navegación de altura y con ello superar el inconveniente de la navegación hacia Occidente, directa y sin puntos fijos de referencia, como planteaba el trabajo de Guerrero (2004); $4 .^{\circ}$ porque para mediados del siglo XIII a.C., muchos palacios han empezado ya a desaparecer (10).

En una reciente revisión de las cerámicas a torno del yacimiento cordobés, Perlines (2005: 480- 481) señala que éstas aparecen en dos momentos de la vida del yacimiento, el primero caracterizado por la presencia de cerámicas Cogotas I y el segundo, en el que las decoraciones Cogotas van siendo progresivamente sustituidas por impresiones digitales o pintura monocroma. Dado que las dataciones C14 (Ruiz-Gálvez 1995: 82-83) sitúan las cerámicas Cogotas I no más allá del 1000 cal B.C. tenemos al menos un límite cronológico inferior para estas cerámicas a torno. Dicho de otro modo, cabe pensar que estas cerámicas a torno no decoradas, así como los dos fragmentos de cerámica micénica de Montoro, se sitúen en un lapso de tiempo no más antiguo de 1250 B.C. y no más reciente de 1000 B.C. En apoyo de este argumento estaría el paralelo chipriota y no micénico propuesto por Torres (2008), para las cerámicas a torno de Purullena, porque indicaría idéntica procedencia para las restantes cerámicas a torno no decoradas del Sudeste peninsular, ya que, de acuerdo con los análisis por activación neutrónica (vide pp. 98-99), todas proceden del mismo taller. Torres (2008: 62-63) da por buena esta fecha obtenida sobre trigo, y por tanto de vida corta, porque la situaría en el siglo XIV (1420-1310 B.C.), y por tanto casaría

(10) José Luis López Castro (2008) y Mariano Torres (2008) también discuten las dataciones C14 de Montoro y Purullena. 
con la del paralelo chipriota que él propone para el recipiente de Purullena, que aparece en el pecio de Uluburum de fines del siglo XIV B.C. y en la casa minóica XA del puerto cretense de Kommos del siglo XIV a.C. Pero, como Torres no ignora, a $1 \sigma$ el margen de imprecisión de la datación... aumenta. Tal como el autor señala (Torres 2008), la jarra pithoide chipriota se fecha en Kommos y Uluburum en el siglo XIV a.C. Ignoramos si esta jarra pitoide pudo haber tenido una vida larga $\mathrm{y}$ no estrictamente restringida al siglo XIV a.C., como ocurre con otros muchos contenedores, como los pithoi chipriotas que aparecen en Uluburum a fines del siglo XIV a.C., en Gelidonya a mediados del siglo XIII a.C. y en Punta Iria a fines del siglo XIII a.C. (Vichos y Lolos 1997: 323-325; Åström 1999).

Más interesante me parece el hecho, deducible del trabajo de la mencionada autora (Perlines 2005), de que estas cerámicas a torno habrían estado, bien llegando o bien produciéndose localmente a lo largo de un lapso relativamente largo de tiempo, porque ello sugiere, como en el caso italiano (Vagnetti 1993, 1998, 2000), la presencia, estacional o permanente, de extranjeros asentados entre indígenas. Como ya señaló en su día Vagnetti (1993: 152, 1998: 71; Bernardini 1991, 1993), hay técnicas, y en ellas se incluye el trabajo del torno, que sólo se aprenden mediante un estrecho contacto maestro/alumno. Si así fuera, ello podría explicar las aparentes imitaciones indígenas a mano, de cerámicas a torno que Perlines (2005: 487) identifica en el estrato VI de Montoro y, tal vez, en otros yacimientos del Sudoeste andaluz.

Tampoco está claro el contexto, precolonial o no, de un soporte a torno procedente de Carmona (Pellicer y Amores 1985), que no ha sido sometido a análisis por fluorescencia de rayos X (Perlines 2005: 483). Como tampoco está claro si es submicénico o jónico un recipiente a torno, de forma globular, con dos asas y decoración de bandas y ondas pintadas en marrón, hallado, por desgracia, fuera de contexto arqueológico en el cerro de San Juan de Coria (Sevilla) (Belén 1993: 42 y Fig. 4 n. ${ }^{\circ} 4$ ) y otros recipientes a torno de contexto igualmente poco claro, dados a conocer en los últimos años (Almagro y Fontes 1997: Fig. 5 n. ${ }^{\circ}$ 1; Molina 1978).

En resumen, lo que estoy haciendo en estas líneas es tomar partido o definir cuál es mi posición al respecto, esto es, plantear que, de acuerdo con el registro arqueológico del que en la actuali- dad disponemos, no me parece factible creer en una relación, más o menos continuada y significativa, entre las potencias mediterráneas y sus confines -esto es, la Península Ibérica, y a través de ella el mundo atlántico-, hasta los momentos últimos de la Edad del Bronce o, posiblemente, la Edad del Hierro (11). Es decir, no antes de mediados del siglo XIII a.C. en el que los palacios micénicos empiezan a colapsar, y seguramente ya hacia 1200 a.C., en que el Mediterráneo entra en la Edad del Hierro y en un período de descentralización política (12) que se prolonga hasta mediados del siglo XI/inicios del siglo X a.C., en el que Tiro sobresale como una ciudad-estado gobernada por una oligarquía de príncipes-comerciantes similar al de las ciudades medievales italianas (Aubet 2000). Y ¿por qué en esta época, entre los siglos XIII/XII a.C. y el X/IX a.C.? Porque es cuando empiezo a tener evidencias más abundantes y contextualizadas de relación, directa o indirecta -yo creo que indirecta-, entre el Mediterráneo Oriental y la Península Ibérica. En cuanto a los yacimientos andaluces, salvo los dos fragmentos de cerámica micénica de Montoro, de los que sabemos se fabricaron en la Argólida (vide pp. 98-99), nada sabemos de la ubicación del taller o de la procedencia geográfica de los alfareros que produjeron las cerámicas a torno de Montoro, Purullena o Gatas, y aunque hay que aceptar que aquellos eran foráneos pues conocían el torno, no podemos asumir que, necesariamente, fueran micénicos, dado que hasta la fecha la arqueometría no ha permitido ni ubicar el taller en que se fabricaron ni relacionarlo con formas o tipos de pastas micénicos (13). Por ello, tampoco podemos suponer, sin más, que los dos vasos de cerámica micénica llegaran a Montoro traídos por comerciantes micénicos. Tal vez sí o... tal vez su origen fue otro... quizá chipriota (14) o minorasiático.

Creo significativo que los datos y contextos más abundantes y fiables de comercio mediterráneo prefenicio en la Península Ibérica, nos lleven hacia fechas de transición II/I milenio a.C. (siglo XII a X cal B.C.) y al Sudoeste más que hacia

(11) En cronología mediterránea, no europea.

(12) Bien ejemplarizado en el relato de Wen-Amun.

(13) El paralelo aducido por Torres (2008) es chipriota, no micénico. En Chipre, Rodas y Levante se están produciendo desde HRIIIB cerámicas micénicas además de las locales.

(14) Véase nota 13. Precisamente Torres Ortiz propone un paralelo chipriota para la pátera de Berzocana: "Elementos precoloniales en el Bronce Final de Extremadura". En J. Jiménez Ávila (ed.): Sidereum Ana II (Mérida, mayo 2007), en prensa. 
el Mediterráneo español, porque ello sugiere un interés hacia territorios y productos atlánticos, más allá de la Península Ibérica, a los que podría haberse accedido a través de los sitios portugueses, porque representa la conexión con los mundos marginales del Occidente Europeo en el Bronce Final en cronología europea.

Sin embargo, no quiero transmitir una visión simplista de que la colonización fenicia de Occidente es solamente una etapa más tras las anteriores. Creo, efectivamente, que los fenicios no llegan al azar sino siguiendo unos derroteros y unas rutas comerciales preexistentes y bien conocidas en el Mediterráneo, y que se solapan a rutas indígenas anteriores y a una demanda indígena previa. Pero la naturaleza del asentamiento y el tipo de comercio que practican son de naturaleza totalmente diferentes. Por ello, rechazo el término "precolonización".

\section{¿QUÉ EVIDENCIAS DE “COMERCIO" PREFENICIO POSEEMOS, EN QUÉ FECHAS, HASTA QUÉ PUNTO RESPONDE A ALGO NO ESPORÁDICO SINO REGULAR?}

En este apartado trataré de enumerar una serie de evidencias de objetos mediterráneos que tienen un nexo común:

- Todos ellos aparecen bien contextualizados arqueológicamente. No se trata por ello de hallazgos aislados sino que proceden de excavaciones arqueológicas recientes y es posible reconstruir sus asociaciones y poseen además, en la mayoría de los casos, dataciones radiocarbónicas.

En primer lugar analizaremos los objetos de hierro en contextos de Bronce Final portugués, recientemente revisados por diversos autores (Tab. 1), por lo que a ellos remito a aquellos lectores interesados en una información más extensa (Senna-Martínez 2000; Vilaça 1995: 349-352, 2006, 2008; Ruiz-Gálvez 2005b; Torres et al. 2005).

En la tabla 1 se recogen objetos de hierro en castros portugueses, en ocasiones asociados a otros elementos exóticos como marfil, pasta vítrea o ámbar báltico (15). En Outeiro de Beijós (dist. Viseu), se recuperaron fragmentos de objetos de hierro en dos momentos habitacionales su-

(15) Que yo creo que llegan por el mismo conducto -el Mediterráneo- a través de la ruta del ámbar, que el hierro y la fayenza. cesivos bien estratificados. La fase más antigua, correspondiente al Bronce Final con las típicas cerámicas de decoración incisa geométrica, tipo Baiôes-Santa Luzía, se asocia a fragmentos de cuchillos de hierro y a dos dataciones C14 (Sac 1539 y 1566). Sobre ella se sitúa un nivel habitacional más reciente, asimismo con cerámica Baiôes-Santa Luzía pero unida a una fíbula de doble resorte que indica el primer impacto fenicio en la zona (Sac 1524) (Senna-Martínez 2000). Las cuatro dataciones siguientes proceden del castro de Moreirinha (dist. Idanha-a-Nova), excavado por Raquel Vilaça $(1995,2006,2008)$. El sitio es un pequeño asentamiento del Bronce Final con abundantes cerámicas bruñidas externas, tipo Lapa do Fumo, pintadas Carambolo, Cogotas I, objetos de bronce y hierro que delatan actividades de fundición y reciclado de chatarra, así como ámbar báltico. De acuerdo con la excavadora, los objetos de hierro procedían de la capa 2 a la que se asocian las dataciones ICEN 825 y Oxa 4085, esta segunda menos fiable por su alta desviación estándar. Las otras dos muestras proceden de la capa 3 infrapuesta y más antigua, las ICEN 834 y GrN-19669. Son en realidad la misma muestra dividida y datada por diferentes laboratorios, pero con resultados no coincidentes debido al tratamiento de homogeneización a que fue sometida la muestra (Vilaça 1995: 237). En todo caso, ICEN 835 a la que se asocian los objetos metálicos señala claramente un momento anterior a cualquier presencia fenicia en la zona.

Las siguientes cuatro dataciones proceden del castro de Monte do Frade (dist. Penamarcor), de nuevo excavado y publicado por Vilaça (1995, 2006, 2008). De la capa 3 procede un cuchillo de hierro afalcatado, acompañado de material del Bronce Final local, sin que ningún otro objeto permita pensar en la presencia fenicia. A este nivel se asocian cuatro dataciones radiocarbónicas, una escasamente indicativa por su alta desviación estándar (ICEN 970). Sin embargo, las otras sí lo son. Se trata de las muestras ICEN 969, ICEN 971 y GrN-19660, que señalan una fecha para la capa 3 en la que aparece el cuchillo de hierro, claramente anterior a cualquier presencia fenicia en el área.

Siete dataciones obtenidas sobre madera del astil de varias lanzas del depósito de Ría de Huelva permiten situar el conjunto, bastante homogéneo, a mediados del siglo X B.C. y con él, algunos fragmentos de hierro que se recuperaron con el conjunto y que no hay razones para pensar que no formaran parte del mismo. 


\begin{tabular}{|c|c|c|c|c|c|c|c|c|c|}
\hline Módulo & $1 / 5$ & $1 / 3$ & $2 / 5$ & $1 / 2$ & $2 / 3$ & $5 / 6$ & 1 & 2 & 4 \\
\hline Peso* & 1,86 & 3,1 & 3,72 & 4,65 & 6,2 & 7,75 & 9,3 & 18,6 & 37,2 \\
\hline Pragança & 1,82 & 3,17 & 3,87 & $(4,10)$ & 6,28 & - & 8,70 & 18,72 & - \\
\hline & 1,86 & $\begin{array}{l}3,20 \\
3,29\end{array}$ & 4,08 & $\begin{array}{l}4,34 \\
4,65 \\
4,79\end{array}$ & & & 9,32 & & \\
\hline Monte do Trigo & - & - & - & - & - & - & 9,54 & 19,48 & 37 \\
\hline Senhora da Guia, Baiôes & - & - & - & - & 6,2 & - & 9,1 & - & - \\
\hline Abrigo Grande das Bocas & - & - & - & 4,92 & - & - & - & - & - \\
\hline Penha Verde & - & - & - & 4,54 & - & - & - & - & - \\
\hline Moreirinha & - & - & 3,98 & - & - & - & - & - & - \\
\hline Castro da Ota & - & - & - & - & - & 8 & - & - & - \\
\hline Canedotes & - & - & 3,8 & - & - & - & - & - & - \\
\hline
\end{tabular}

Tab. 2. Ponderales de los castros indígenas portugueses (según Vilaça 2003: Figs. 1 y 2) ordenados respecto al ponderal ugarítico (tabla elaborada por Eduardo Galán).

Menos indicativa es la datación del depósito de Baiôes, debido a la alta desviación estándar -130 años- (Kalb 1974-77). No obstante, el depósito que, entre otras cosas, contenía un cuchillo de hierro enmangado en un hacha tubular de tipo atlántico, no parece contener elemento alguno de tipología o cronología fenicia. Tampoco el castro en el que apareció pese a lo parco de su publicación, parece haber sobrepasado el final de la Edad del Bronce (Coelho 1986), por lo que (contra Senna-Martínez 2005) no veo razón alguna para atribuir el hierro a época fenicia.

Otros sitios con dataciones $\mathrm{C} 14$ recientemente publicadas son Quinta do Marcelo (Almada) (Senna-Martínez 2000), con el hallazgo de un fragmento de hierro en un fondo de cabaña en contexto prefenicio asociado a una datación (ICEN 924) que, calibrada a $2 \sigma$, equivale a $1012-763$ cal B.C.; Monte do Trigo (dist. Idanha-a-Nova) (Vilaça 1995, 2006), del que Vilaça (2003) publica una serie de dataciones de Bronce Final para hallazgos de objetos de bronce y hierro, entre ellos ponderales, y Rocha do Vigio 2 (Reguengos de Monsaraz) (Vilaça 2006), con un escoplo de hierro en contextos de Bronce Final que, aunque sin dataciones absolutas hasta el momento, cabe atribuirle fechas similares, entre los siglos XII-X B.C., como en los casos precedentes. Algo semejante cabe suponer para el sitio de Castelejo (Beira Interior) (Vilaça 1995: 111), de cuya capa 1 procede un fragmento de clavo de hierro de cabeza circular. Lamentablemente, ninguna de las tres dataciones radiocarbónicas del sitio son útiles por proceder de madera seguramente fósil (Vilaça 1995: 123). Sin embargo, como en Baiôes, nada permite pensar en un momento tardío con presencia fenicia para el hallazgo de hierro.

Asimismo, como recordaba Vilaça (2006), los recientes hallazgos de hierro, bien contextuali- zados en ambientes indígenas del Bronce Final de Portugal, permiten reexaminar viejas evidencias, como la del castro salmantino del Berrueco (Maluquer 1958), en cuya vivienda Be2 se documentó un conjunto de objetos metálicos, tal vez un depósito, asociado a cerámica Cogotas I y a cuatro objetos de hierro. Ya en su momento, Almagro (1993) reivindicó su cronología prefenicia, lo que, visto que las dataciones C14 para el mundo Cogotas I de la Meseta no van más allá del 1000 cal B.C. (Castro et al. 1996; Ruiz-Gálvez 1995, 1998a: cuadro A2) y los contextos radiocarbónicos de los hallazgos de hierro en sitios del Bronce Final portugués, no parece desacertado. Otras dataciones, esta vez para presencia de hierro en sitios indígenas, si bien ya claramente en un momento en que existen colonias fenicias (Tab. 1), vendría a reforzar el contexto antiguo y precolonial de los sitios antes mencionados (Ruiz-Gálvez 2008; Torres et al. 2005).

No menos interesante es la documentación de ponderales en castros portugueses, algo que, nuevamente, debemos al buen hacer de Raquel Vilaça (2003: Figs. 1 y 2) (16) (Tab. 2). Ya no se trata de objetos de bronce $u$ oro que se agrupan respecto a unidades, múltiplos o divisores de supuestas unidades de peso (Ruiz-Gálvez 1995, 1998a, 2000, 2003; Galán y Ruiz-Gálvez 1996; Galán 2005), algo que los escépticos pueden considerar aleatorio, o que se ajustan a la unidad que uno desea... (17).

En este caso, el juego de ponderales es incuestionable y su módulo parece corresponder a la

(16) E. Galán y M. a L. Ruiz-Gálvez, "Writing, ciphers, selfconciousness and private trade at the eve of the Phoenician colonization". Actas del VI International Congress of Phoenician and Punic Studies (Lisboa 2005), en prensa.

(17) Las formas de los pesos portugueses tienen buenos paralelos en el mundo egipcio levantino de la Edad del Bronce. Véase Pétrie 1926 y Court-Marty 1990. 
unidad de $9,3^{*} \mathrm{~g}$, esto es, al siclo sirio o ugarítico (Vilaça 2003: Figs. 1 y 2) (Parise 1970-71, 1984), muy común en el Levante, Chipre y Ugarit hasta fines de la Edad del Bronce en que el siclo hitita de $11,75^{*}$ g pasa a ser la divisa dominante (Zaccagnini 1991) y documentado en los pecios de Uluburum y Gelidonya (Pulac 2000; Bass 1967). Por ello y por el hecho de ser el sistema de peso dominante en el área levantina y no en el Egeo, este estándar reviste un inusitado interés, pues nos remite a la misma región geográfica de donde luego procederán los primeros colonos asentados en la Península Ibérica, si bien el contexto radiocarbónico de los sitios portugueses y el propio estándar sirio nos sitúan en momentos cronológicos anteriores al I milenio a.C. y, por tanto, a la colonización fenicia. Que no se trata de un hecho aislado lo confirma el que este mismo ponderal se documente en las excavaciones del casco antiguo de Huelva (González de Canales et al. 2004: 154-155, Láms. XXXVIII, n. ${ }^{\circ} 10$ a 13 y LXIV, n. ${ }^{\circ} 21$ a 24). Aunque, debido a que los materiales a los que se asocia el juego de ponderales onubense no proceden de excavación sistemática (González de Canales et al. 2004: 23-24), no posemos información sobre su contexto arqueológico preciso, cabe pensar, por cronología tipológica de las cerámicas y de algunos elementos significativos, como las fíbulas de doble resorte, que nos hallamos en un contexto de importaciones mediterráneas que se desarrollan en un lapso relativamente largo de tiempo situable entre finales del II milenio a.C. y las primeras colonias fenicias. Dentro de este marco, y aunque soy consciente de que estoy meramente especulando, pues ignoramos el contexto estratigráfico y las asociaciones arqueológicas precisas de estos pesos de plomo, me parece más factible pensar que los ponderales se asocien a los materiales chipriotas, levantinos o centroitálicos precoloniales, es decir, anteriores a los asentamientos coloniales fenicios en la Península Ibérica, pues a estos últimos se asocia otro patrón de peso: el siclo fenicio de 7,9* g, como lo atestiguan Cerro del Villar o Cancho Roano (Aubet 2002). Podemos precisar el contexto cronológico al que se podrían adscribir estos ponderales onubenses, gracias a la presencia entre los materiales cerámicos documentados en el casco antiguo de Huelva de cerámicas vilanovianas y sardas geométricas. Las dataciones dendrocronológicas y radiocarbónicas para sitios del Norte y Centro de Italia, permiten situar la fase
Vilanoviana hacia el siglo XI B.C., de acuerdo con Peroni (1994: 215 y Fig. 80), o mediados del siglo X B.C., según Pacciarelli (1996: 186 y Fig. 1). En cuanto a las geométricas sardas, los contextos datados radiocarbónicamente permiten situar estas entre el siglo $\mathrm{X}$ y fines del IX a.C. (Rubinos y Ruiz-Gálvez 2003). En ambos casos, pues, antes del asentamiento de colonias fenicias en Occidente, y como los propios materiales onubenses muestran, en un tipo de comercio oportunista, a través, seguramente de intermediarios (18), multiétnico y sin palacio o potencia comercial dominante. Algo similar cabe pensar del hierro y las importaciones mediterráneas en los castros del Bronce Final portugués, antes revisados.

\section{SOBRE EL PAPEL DE LOS COMERCIANTES INDEPENDIENTES EN LA EXPANSIÓN DE LAS RUTAS MEDITERRÁNEAS HACIA LA PENÍNSULA IBÉRICA}

Se ha considerado tradicionalmente desde Polanyi (1963), que el comercio en el mundo antiguo se basó en el tributo, la reciprocidad o intercambio de regalos y la redistribución, siempre controlados por el palacio o el templo (Liverani 2005: 205 ss.), por lo que no hubo iniciativa privada ni comercio independiente.

Sin embargo, el registro arqueológico del Próximo Oriente permite pensar que los comerciantes, fuera cual fuera su posición -dependiente o independiente-, ocuparon en más de una ocasión un lugar relevante dentro de su sociedad. Ejemplos de ello son, entre otros, los siguientes: la tumba de Vaphio (Laconia), un tholos cuyo ajuar se conservó in situ al ser sellado por losas tras el enterramiento (Tsountas y Manatt 1897: 144 y ss. y Lám. 8). El conjunto de objetos estaba formado, además de por los famosos vasos de oro, otros recipientes en bronce, alabastro o cerámica, armas, etc., por un cetro, un juego de sellos y diez pequeños discos de cobre de cinco tamaños diferentes, identificados como pesos de balanza, lo que, de ser correcta la interpretación, señalaría una estrecha relación entre el ejercicio del poder y el control por el peso de materias primas valiosas. La tumba se data por criterios arqueológicos en el HRI, lo que equivale a decir, mediados del siglo XVII cal B.C. (Manning 1991).

(18) Lo que los anglosajones denominan tramping trade. 
Otro hecho arqueológicamente atestiguado es la relación entre pesos - por tanto, números- y escritura. Así, en el transcurso de las campañas de excavación de 1954 y 1955 en Ugarit, Schaeffer (1962: 93 y ss.) puso un especial empeño en localizar tridimensionalmente todos y cada uno de los objetos encontrados en el transcurso de sus excavaciones en las alas sudoeste y nordeste del palacio. Ello permitió constatar la estrecha asociación de las tablillas en escrituras cuneiforme y alfabética a instrumentos de orfebre y de eboraria y a pesos de balanza, estos últimos correspondientes todos ellos al siclo sirio o ugarítico de $9,3^{*} \mathrm{~g}$. A la autora de estas líneas el hecho le sugiere un estrecho control -mediante pesado y anotación-, de las materias primas preciadas elaboradas por los artesanos de palacio. Pero, ¿los que pesaban, sabían anotar el resultado de sus operaciones?, esto es, ¿sabían escribir? Evidentemente, no puedo responder taxativamente que sí, pero no es improbable que quien supiera escribir, también supiera contar, pues existe una estrecha relación entre la escritura y el cálculo numérico (Senner 1992: 17; SchmandtBesserat 1992; Green 1992: 55). He recogido en varios trabajos la cita de Goody (1987: 82 y 5455), acerca de la tendencia a jerarquizar, a ordenar en filas y columnas y a establecer relaciones que letras y números comparten. En idéntico sentido, Green (1992: 55-57) señala cómo en Mesopotamia, para fines del período arcaico, las tablillas se dividieron en columnas y subcolumnas que se leían de izquierda a derecha y dentro de ellas, en líneas o cajas, que se leían de arriba abajo, para que cada tipo de dato tuviera su ubicación específica dentro de una caja o de una columna. Así las cantidades se escribían en el ángulo superior izquierdo y los títulos o nombres de los supervisores, en la base de la columna. Pues, como afirma Cardona (1994: 134): "la escritura suministra a quien la posee también un modelo que organiza y clasifica los conocimientos, una especie de casillero en el cual se disponen las cosas que hay que recordar".

Que la relación entre ambas habilidades no era un hecho aislado, lo sugiere también la evidencia procedente de un grupo de tumbas de cámara del Chipriota I-II (1450-1200 a.C.) de Ayia Irini (Pecorella 1977; Keswani 2004). Aunque algunas han sido saqueadas, el meticuloso trabajo de excavación de Pecorella permite distinguir los diferentes momentos de uso funerario, así como los ajuares asociados a cada cuerpo. Especialmente interesantes son las tumbas $3,11,20$ y 21 , todas con un enterramiento fundacional, probablemente de un varón, asociado a un rico ajuar de objetos locales e importados, entre ellos copas del HRII, oro y plata, huevos de avestruz, objetos asociados a la fundición y trabajo del metal, al pesado, a la escritura y al sellado, esto es, al comercio extranjero y a la burocracia. La tumba más rica $-21-$ nos da una imagen general de la necrópolis, repetidamente reutilizada por los miembros de una misma familia o grupo aristocrático. Entre los numerosos ajuares destaca un estilo de bronce con punta redondeada y extremo en forma de cincel, similar a los hallados en Bögazköy (Symington 1991: 114) y usado para escribir y borrar en una tablilla de cera, seguramente similar a la rescatada del pecio de Uluburum. Los textos hititas y ugaríticos registran el empleo de este tipo de soporte, pero no podemos excluir su uso en otras partes, como el propio hallazgo de Ayia Irini permite sospechar. Diversos autores han señalado el probable uso de soportes perecederos -bien madera, cera o papiro- en Micenas para escribir Linear B, aunque es muy improbable que se conserven en el registro arqueológico, si bien sendos fragmentos de gozne de bronce procedentes de Pilos y Cnossos, han sido interpretados como pertenecientes a posibles tablillas (Utchitel 1988: 21; Stroud 1992: 110; Manessy-Guitton 2000: 220; Schnapp-Gourbeillon 2002: 265). Otros objetos sobresalientes de la tumba 21 de Ayia Irini eran una balanza de bronce y un juego de pesas correspondientes al ponderal sirio, un sello sirio o de estilo sirio muy gastado (Smith 2003: 298), fragmentos de lingotes, chatarra y tenazas de metalurgo. Objetos similares se han encontrado en los enterramientos más antiguos de las otras tumbas: una balanza y un juego de ponderales sirio en la tumba 20; ponderales sirios y minorasiáticos y objetos de fundidor en la tumba $11 \mathrm{y}$, por último, un juego de ponderales eblaíta, mesopotámico, minorasiático y sirio, así como material de fundición en la tumba 3 (Parise 1977: 293-296). Finalmente, un cetro de basalto de probable factura egipcia procede del nivel 4 de enterramientos de la tumba 21 (Kouru 1994: 208). De nuevo, la evidencia de Ayia Irini permite asociar el ejercicio del poder con la metalurgia, el comercio foráneo y la burocracia (19). Otras tumbas chipriotas, tanto del Bronce Tardío y Final como de la Primera Edad del Hierro en Paleokastro, tumba 1

(19) Véase nota 16. 
de Morphou Toumba tou Skourou, Enkomi, Maroni, Amathus, Palaeopaphos-Skales y Salamina (Schaeffer 1952; Yon 1971; Quilici 1990; Chavane 1990; Courtois 1983) reflejan una evidencia similar. Todas ellas corresponden a una élite de poderosos comerciantes y burócratas, y apoyan la creencia de Shelmerdine (1998: 293) de que chipriotas y cananeos fueron los protagonistas de la mayor parte del comercio en el Mediterráneo Oriental a fines de la Edad del Bronce (20), incluso si, en ocasiones, trabajaron por cuenta de otras potencias. Pues también el registro arqueológico cananeo contiene en un número no infrecuente de casos, evidencias relativas a ricas tumbas de comerciantes-guerreros-orfebres-burócratas: como, por ejemplo, el grupo de tumbas del Bronce Final de Akko (Ben-Arieh y Edelstein 1977), la tumba 912B de Megiddo, también datable en el Bronce Final (Guy 1938: 69-72), o la tumba familiar fenicia, ya en la Primera Edad del Hierro, de Achziv (Mazar 2004), cuyo nivel de enterramiento más antiguo contiene los cuerpos de un guerrero, un orfebre-comerciante y restos de un tercer individuo (21). En algunos casos, como acontece con el grupo de tumbas de Akko, la meticulosa excavación llevada a cabo permite reconstruir la posición exacta de los ajuares respecto de los cuerpos, y con ello corroborar que ciertos objetos, como los sellos que se llevaron colgados del cuello, o juegos de pesas, que aparecen concentradas junto a la cadera o las piernas -lo que sugiere que se hallaban guardados en una bolsa-, eran posesiones personales (Beck 1977: 63-69). El hecho no es baladí porque indica, al igual que la evidencia funeraria de Ayia Irini, que algunos comerciantes, al menos en los pequeños estados periféricos a las grandes potencias políticas del Mediterráneo, eran mucho más que funcionarios dependientes. Tal vez, precisamente por eso, ni Chipre ni los pequeños estados periféricos cananeos, cuyo sistema político era menos centralizado, colapsaron a fines de la Edad del Bronce (22). Por el contrario, otros como Ugarit, donde los textos y la evidencia arqueológica (23)

(20) Seguramente, los albores de la Edad del Hierro.

(21) Véase nota 16.

(22) Cadogan (1998: 13), como muchos otros, sugiere que para fines de la Edad del Bronce y a pesar de las referencias en los textos hititas, Chipre era políticamente independiente de las grandes potencias territoriales de la época.

(23) Hallazgo de correspondencia diplomática del siglo XIII a.C. fuera de los archivos de palacio y en casas privadas de aristócratas o escribas reales como Rap'anu, Ouzzinou, Raša- de los siglos XIV/XIII a.C. muestran abundantes indicios de propiedad privada de la tierra y del comercio, frecuente arrendamiento del cobro de los impuestos reales por particulares, creciente número de "gentes del rey" (Heltzer 1984: 162 y 185), así como cierta vulnerabilidad del Estado frente a las acciones piráticas de sus vecinos, los Lukka (Bryce 1992: 129), y un creciente recurso al "alquiler" de tropas mercenarias (Singer 2000: 24); o Hatti, donde Hawkins (2002) señala abundantes pruebas de debilidad de los últimos dinastas hititas (24), sí acabaron por colapsar. Incluso Egipto, que no se llegó a hundir, sí mostró signos de la debilidad de los faraones frente a sus propios súbditos y a los pueblos sometidos. Helck (1987) señala cómo tras el período de Amarna, los faraones ramésidas devolvieron bienes y tierras a los templos, quienes se vieron obligados a dar salida mediante el comercio a tan repentino incremento de riqueza, con la consiguiente pérdida estatal del monopolio comercial. El proceso de debilidad continuó con la extensión de esa concesión también a altos cargos de la administración del ejército. Éstos rompieron el monopolio estatal sobre ciertas mercancías y materias primas, ofreciéndolas a un público menos restringido y vendiendo sus derechos de comercio a agentes asiáticos. A partir de la dinastía XIX (ca. 1295-1175 a.C.), las mercancías egipcias se intercambiaron en circuitos cada vez más amplios, produciendo aumento de la demanda y escasez de medios con los que comprar y vender. La consecuencia fue la subversión de los valores morales. Son abundantes las referencias de la época a robos, o expolios de tumbas y templos. Otro indicio de vulnerabilidad es la política de construcción de fortalezas entre comienzos del siglo XIII a.C. y comienzos del siglo XII a.C., esto es, entre los faraones Seti I y Ramsés III, para contener las invasiones libias, tanto por el interior como por la

pabu, Yabinu o Urtemu (Heltzer 1984; Courtois 1988: 390-4; Caubet 2000: 43-44; Yon 2003: 47). Un claro indicio -opino de la existencia de propiedad privada y de la dificultad del Estado para controlar a sus servidores.

(24) El tratado (ca. 1250 a.C.) entre Tudkhalia IV y su primo el rey de Tarhuntassa en que el primero hace muchas concesiones; las expediciones de época de Tudkhalia IV contra los Lukka recogidas en la inscripción de Yalburt (Konia), las campañas de Shuppiluliuma II contra los Lukka y contra Tarhuntassa (ca. 1200 a.C.) descritas en inscripciones de Bögazköy, o la evidencia procedente de los archivos de Karkemish acerca de los procesos de independización a lo largo del siglo XIII a.C. respecto a Hatti de los pequeños estados sirios vasallos. Así como la dependencia de mercenarios en el ejercito y el transporte. 
costa (Snape 2003: 64; Richardson 1999: 151 y nota 14) y la dependencia de mercenarios para el ejercito y el transporte. Ése es, por último, el caso de los pequeños estados micénicos de los que, a pesar de la carencia de información escrita de tipo político o diplomático (Utchitel 1988: 20), ciertos datos permiten sospechar el agotamiento del sistema administrativo centralizado que condujo al colapso. Por ejemplo, Hiller (1988: 53-60), basándose en las tablillas de Pilos que reflejan el último año de vida del palacio (25), en las que se elaboraron listados del personal dependiente directa o indirectamente de éste, calcula que bajo una u otra condición aparecen listados en las tablillas 4.000 individuos... Demasiados para una población total estimada de 50.000 personas en el territorio de Pilos. Si, además, el comercio pesado lo llevaban a cabo agentes intermediarios no micénicos, como lo evidencian la cerámica micénica fabricada en Creta, Chipre, Rodas o Italia (Vagnetti y Jones 1988; Jones y Vagnetti 1991), o las marcas en chiprominoico de algunas cerámicas micénicas del Levante (Gillis 1995; Manning y Hulin 2004: 281-284), y si, como algunos datos apuntan, al menos en los siglos XIV/XIII a.C. existían en Micenas comerciantes privados (Manning y Hulin 2004: 282) (26), nos encontramos claramente en una situación bien descrita en la ley de rendimientos decrecientes (Tainter 1990: 93), que conduce al colapso (27).

\section{ENTONCES, ¿SON O NO SON MICÉNICOS LOS RESPONSABLES DE LA CERÁMICA MICÉNICA DE LA CERÁMICA A TORNO NO DECORADA DE MONTORO?}

Pues, evidentemente, la autora de este trabajo no fue testigo directo o indirecto de tal hecho, por lo que no puedo responder a la pregunta, aunque sí argumentar, a partir de los datos y razones que he ido exponiendo precedentemente, por qué pienso que no son micénicos sino chipriotas o una koiné de agentes orientales (con el probable concurso de intermediarios occidentales), quienes están detrás de estas cerámicas. Y lo resumo:

(25) Las tablillas se conservaban sólo un año y se renovaban cada año administrativo.

(26) Archivos y sellos en casas particulares fuera de la ciudadela de Micenas (Uchitel 1988: 20; French 2004: 71-73).

(27) Otro partidario de las causas internas del colapso es Ch. G. Doumas (1998: 129-30).
1. ${ }^{\circ}$ La mayor parte de las dataciones asociadas a dichas cerámicas, o a la presencia de otras importaciones mediterráneas en la Península Ibérica, se concentran en fechas en las que los palacios micénicos o habían desaparecido o empezaban a dar muestras de agotamiento.

2. ${ }^{\circ}$ Salvo los dos pequeños fragmentos de cerámica pintada de Montoro, ninguna otra importación nos remite a Micenas. Las cerámicas a torno no decoradas de Montoro, Purullena, etc., carecen hasta donde yo sé de paralelos exactos y tampoco está identificada la procedencia del taller, por lo que no se puede presumir gratuitamente que sean micénicas, más cuando como los análisis arqueométricos sobre cerámicas micénicas del HRIIIB y otras a torno de Italia señalan, en muchos casos proceden bien de talleres locales o bien de rodios, cretenses o chipriotas, pero no griegos (Vagnetti y Jones 1988; Jones y Vagnetti 1991), y cuando la cerámica "micénica" del HRIIIC es, en Oriente como en el Mediterráneo Central, de fabricación local. En todo caso, si el paralelo propuesto por Torres (2008) para las de Purullena es correcto y si aceptamos los resultados de los análisis por activación neutrónica (Perlines 2005) que señalan un mismo origen para todas ellas, cabe pensar en chipriotas u otras gentes de Asia Menor, pero no en micénicos.

3. ${ }^{\circ}$ La mayor parte de las evidencias de comercio mediterráneo prefenicio en la Península Ibérica consisten en objetos de hierro, pero la siderurgia era desconocida en época micénica.

4. ${ }^{\circ} \mathrm{Al}$ contrario de lo que era habitual en el comercio mediterráneo de la Edad del Bronce en el que ciertas manufacturas, en especial, la cerámica, permitían detectar quién estaba detrás de esa ruta comercial (Gale (ed.) 1991), a partir del 1200 a.C. no existen tales marcadores. Ello no quiere decir, a mi juicio, que tras el colapso de los Estados desapareciera el comercio como se viene afirmando. Lo que posiblemente ocurre es que a partir de la Edad del Hierro la naturaleza del comercio fue diferente: privado, oportunista, a través de múltiples agentes y no monopolístico; en definitiva, de naturaleza muy diferente al comercio estatal previo, lo que dificulta identificar a quién pertenece el cargamento y, por lo mismo, resulta complejo detectar rutas comerciales y sus protagonistas (28).

Para entender quiénes pudieron ser responsables de la extensión del comercio mediterráneo hacia la Península Ibérica y en qué fechas -a mi

(28) Véase nota 16. 
juicio- fue ello posible, tenemos que volver atrás, hacia la evidencia arqueológica procedente de esas tumbas de comerciantes a las que antes he aludido: $10^{\circ}$ Todas ellas corresponden a individuos de posición social elevada a juzgar por los ajuares que se les asocian. 2. ${ }^{\circ}$ En algunos casos se enfatiza en ellos el papel de guerreros o de líderes y además se entierran con los símbolos del comercio y la administración: juegos de pesos, sellos y, en el caso de Ayia Irini, estilos. 3..$^{\circ}$ Todas ellas, además, aparecen en áreas periféricas a los grandes Estados territoriales mediterráneos de la época, incluido el caso de Vapheio (29). 4. ${ }^{\circ}$ En todos los casos, hay continuidad entre el registro de la Edad del Bronce y el de la Primera Edad del Hierro, en el que también se conocen ricas tumbas de comerciantes-guerreros: entre las necrópolis chipriotas de inicios de la Edad del Hierro, la tumbas 67 y 89 de Paleopaphos-Skales de mediados del siglo XI a.C. (Karageorghis 1983; Courtois 1983; Bikai 1983); de la misma época, la tumba 1 de Salamina (Yon 1971: 19-20); algo más reciente, del chiprioarcaico (750-600 a.C.), la tumba 367 de Amathus. Otra tumba de esta necrópolis, la 523, de cronología más antigua -Chiprogeométrico I (1100-900 a.C.)-, contenía una fíbula de codo y un asador articulado atlántico (Karageorghis y Lo Schiavo 1989) (30). Es el caso fenicio ya mencionado anteriormente, de la tumba familiar de Achziv (Mazar 2004), cuyos enterramientos más antiguos, del siglo X a.C., correspondían a dos o tres individuos: un guerrero con armas de hierro; un orfebre-comerciante a juzgar por el juego de pesas pertenecientes a múltiplos o divisores del siclo fenicio, el juego de platillos de balanza y la fina joyería hallada junto a él; y posiblemente un tercer individuo, a quien podrían corresponder otros objetos significativos, como un sello cónico de tipo arcaico, perforado para colgarlo y una fíbula de codo de tipo Huelva como las de Sicilia y la Península Ibérica; por último, tenemos el caso de la necrópolis de época protogeométrica de Lefkandi (31) en la isla griega de

(29) Vapheio no está conectado con ningún gran centro político micénico. Por otra parte, autores como Susan Sherratt (2001), creen que los reinos micénicos tienen características más propias de jefaturas que de auténticos estados, lo que explicaría que sus palacios sean menores y no se parezcan ni a los cretenses ni a los asiáticos (Killian 1987).

(30) Tipo que, a mi juicio, es originario de la Península Ibérica, pues es el único sitio, además de la tumba de Amathus, donde estos asadores no aparecen amortizados como chatarra (Ruiz-Gálvez 1998a: 284 Figs. 89-90, 1998c: 110 Figs. 8 a y b).

(31) Nuevamente un área periférica a los palacios micéni-
Eubea. Una de las tumbas más interesantes de la necrópolis, la 79 (Popham y Lemos 1995), es la incineración de un aristocrático individuo, acompañado de sus armas y de un juego de pesos de balanza que, a mi juicio, corresponden el ponderal hitita o minorasiático (Ruiz-Gálvez 2005a: 266-67 y Fig. 8).

Todo ello prueba en mi opinión, que en los pequeños reinos mercantiles periféricos a los grandes estados territoriales, los comerciantes disfrutaron durante la Edad del Bronce de un estatus aristocrático, como también lo poseían ciertos escribas-funcionarios en Mesopotamia o Egipto, pero que siguieron gozando de esa condición privilegiada durante la Edad del Hierro y, además, de sus ajuares se deduce que pudieron actuar como agentes privados. Que estos individuos amén de contar sabían posiblemente escribir, lo indicaría no sólo el estilo de la tumba 21 de Ayia Irini (vide p. 106), sino el propio testimonio del pecio de Uluburum, del que se rescataron dos juegos completos de balanza de factura egipcia -uno de ellos aún guardado en su estuche de madera-, más fragmentos de un posible tercer juego; tres juegos completos de tres sistemas ponderales diferentes, así como dos tablillas de madera con goznes de marfil para escribir sobre cera (Pulac 1997, 2000). Ello señala, bajo mi punto de vista, dos cosas: $1 .^{\circ}$ que en el barco viajaban al menos tres comerciantes, posiblemente de origen cananeo; $2 .^{\circ}$ que sabían realizar cálculos y anotarlos (Ruiz-Gálvez 2005a: 257-258). Dada la fecha del pecio (32) y la nacionalidad de comerciantes y tripulación, no es improbable que la escritura usada fuera la alfabética, una grafía que ofrecía unas posibilidades de "democratización" de la escritura de las que otros sistemas gráficos carecían.

Pues, si ya de por sí el trabajo de escriba exigía un largo proceso de iniciación, en el caso de sistemas gráficos complejos, los cientos de signos de que se componían propiciaba la compartimentación del conocimiento. Debido a que el sistema era tan prolijo, el escriba de turno únicamente conocía y usaba aquellos signos gráficos asociados a su trabajo profesional, lo que hacía de la escritura una operación múltiple (Cardona 1999: 70). Escrituras

cos, donde, en opinión de Snodgrass (2002: 1-9), no se produjo colapso alguno, sino continuidad entre la Grecia Premicénica y el Período Geométrico y un rechazo consciente e intencionado de la cultura micénica.

(32) Existe una datación dendrocronológica para el pecio de 1327+4/-7 B.C. (Manning et al. 2001: nota 38). 
con cientos de signos como el egipcio jeroglífico (400) o el sumerio (600 aunque habitualmente sólo se usaban 300), sólo podrían, pues, ser dominadas por una escasísima minoría y tras largos años de entrenamiento (Moore Cross 1992: 76).

Pero, la otra cara de la moneda es que el manejo de la escritura produce a medio plazo en quienes la poseen, cambios profundos en la forma de recordar, de almacenar y de organizar el conocimiento y, sobre todo, favorece la capacidad de abstracción y de racionalización (Green 1992: 48; Cardona 1994: 134). Como señala Goody (1985, 1990; Maciá 2000), la escritura marca la frontera entre magia y ciencia y entre mito e historia.

Ahora bien, lo que diferenció el alfabeto de otros sistemas gráficos y lo que explica su amplia generalización, es que al reducir sus signos a 28 (y para el siglo XIII a.C. a apenas 22), que tenían además, valor fonético y una posición siempre fija -lo que llamamos orden alfabético- contribuyó a "democratizar" la escritura y a facilitar su aprendizaje y memorización (Moore Cross 1992: 76-77; Goody 2003: 47-50). Con ello rompió el monopolio de la casta de escribas y, seguramente, favoreció a medio plazo el desencadenamiento de procesos de autoconciencia, reconocimiento de identidades diferenciadas, y de emancipación frente a los poderes del Estado (Ruiz-Gálvez 2005a: 268). Siempre me llamó la atención el hecho de que a los habitantes de la costa levantina se les llame genéricamente "cananeos" en la Edad del Bronce, pero que, a partir del 1200 a.C. ya no se hable más de cananeos sino de fenicios, israelitas, filisteos, arameos, etc. (Liverani 1995: capítulos 19, 23, 24 25; Doumas 1998: 131-132). Me pregunto si la difusión de la escritura alfabética en la región entre fines de la Edad del Bronce y los albores de la del Hierro tuvo algo que ver con estos procesos identitarios.

Posiblemente, también relacionado con esos procesos esté el de la aparición de grupos multiétnicos de comerciantes independientes, que a fines de la Edad del Bronce parecen hacer la competencia o incluso "puentear" los establecimientos comerciales estatales, al que repetidamente han venido haciendo referencia diversos autores (Artzy 1994, 1997, 1998; Bauer 1998; Sherratt 1998, 2000). Sobre todo porque, como indica Cadogan (1998: 11; ver también Åström 1998: 84), en el siglo XIII a.C. aparecen muy difundidos en Chipre la escritura y los estándares de peso orientales, junto con otras innovaciones como la construcción de sillares, todas las cuales remiten a Ugarit y a la costa sirio-palestina, la patria del alfabeto.

Es en ese preciso contexto, entre el colapso de los palacios y la instalación de los colonos fenicios en Occidente (ca. 1250-850/825 cal B.C.), y bajo la acción de agentes intermedios de orígenes diversos, donde yo creo que hay que situar la primera llegada de comercio mediterráneo hacia la Península Ibérica. Éste es, también, el contexto en que encajaría, a mi juicio, la iconografía de las estelas de guerrero de nuestro Bronce Final que, como el arte escandinavo, emula una iconografía del poder que, a través de cerámica, telas, maderas pintadas o talladas, pasta vítrea o eboraria, posiblemente empieza a llegar, a provocar fenómenos de emulación y a ser incorporada a los códigos indígenas de representación del poder, aunque, seguramente, muy pocos o incluso, ninguno de esos objetos mediterráneos (carros, liras, escudos, espejos) llegaran verdaderamente a la Península Ibérica (Lám. III, Galán 1993, 2007; Ruiz-Gálvez 1998a cap. 6, 2005a: 261 Fig. 3).

¿Por qué insisto tanto en la importancia de la generalización del alfabeto en el Levante y su posible adquisición por los comerciantes? Porque las capacidades de lectura y escritura no sólo cambian la percepción de la realidad y de uno mismo, sino que permiten el acceso directo -sin intermediarios políticos o religiosos- a la información; en otras palabras, permiten pensar por uno mismo, cuestionar el origen del poder, rebelarse y/o constituir nuevos grupos de poder (Goody 2003: 31-34). Como dije antes, creo que ello está en la base del cambio en el sistema de comercio que se produce a fines de la Edad del Bronce.

En segundo lugar me interesa, porque uno de los objetos recuperados en las excavaciones del casco antiguo de Huelva podría ser un fragmento de tablilla de madera para escribir sobre cera, del tipo de la rescatada en el pecio de Uluburum (González de Canales et al. 2004: 160, Lám. XL, n. ${ }^{\circ}$ 7, foto LXVI, n. ${ }^{\circ}$ 7), y si la interpretación es correcta, este hecho junto a la presencia en el mismo sitio del juego de ponderales sirio, reforzaría la idea de que es una koiné de comerciantes independientes del Levante, pero también seguramente del Egeo y del centro del Mediterráneo (33), la responsable de la extensión de las rutas mediterráneas hacia la Península Ibérica.

(33) Como indicarían los propios materiales eubeos, chipriotas, vilanovianos y sardos de Huelva (González de Canales 


\section{DE LA ESCRITURA DEL SUROESTE (LÁM. III)}

Quiero insistir, para terminar, en la posible relación entre esta presencia de comercio mediterráneo anterior a la instalación de colonias fenicias en la Península Ibérica y los rasgos arcaicos que, en su día, de Hoz (1986) reconoció en la escritura del Sudoeste si bien, en un argumento circular, acabó negando una cronología prefenicia para ella, porque no podía existir en el Sudoeste una escritura de tipo semita antes de la llegada de los fenicios. Pero ahora sí poseemos un contexto arqueológico prefenicio, que haría comprensible los rasgos arcaicos que existen en la escritura del Sudoeste y que remiten a la escritura protocananea, antecedente del fenicio, del arameo y del hebreo, en la cual la dirección de la escritura aún no estaba normalizada y se realizaba indistintamente de izquierda a derecha, de derecha a izquierda, de arriba abajo, de abajo arriba o en bustrofedon (Naveh 1973: 3). Pues bien, la escritura del Sudoeste es redundante y escrita indistintamente de izquierda a derecha, de derecha a izquierda o en bustrofedon (34), rasgos que no aparecen en la escritura fenicia (Naveh 1987).

Si el mantenimiento de la regularidad en las rutas comerciales implica necesariamente que, al menos, los interlocutores de uno y otro lado se entiendan, bien con lenguas pidgin, lenguas francas o vehiculares, o mediante el bilingüismo de los agentes indígenas (35), del mismo modo exigiría que los intermediarios indígenas estuvieran familiarizados con el estándar de peso usado por los extranjeros para el intercambio. Si es así ¿por qué no también con "la otra cara de la moneda": la escritura? (36).

et al 2004) o los sardos del Carambolo (Torres 2004) y de Cádiz (Córdoba Alonso y Ruiz Mata 2005).

(34) También la estela de Nora está escrita en bustrofedon, rasgo que es arcaico.

(35) Courtin (1984: 57-58) cuenta, a propósito del comercio portugués en África a partir del siglo XV, cómo al principio los comerciantes portugueses secuestraban nativos y los llevaban a Portugal para que aprendieran portugués y sirvieran de intérprete en el siguiente viaje. Conforme el comercio fue estableciéndose sobre bases más sólidas se tomó la costumbre de dejar en tierra a un miembro de la tripulación para que fuera reuniendo cargamento para el viaje siguiente. Ello dio lugar a uniones con nativas con el subsiguiente nacimiento de mestizos bilingües, que se convirtieron en mediadores, intérpretes y agentes comerciales.

(36) Cardona (1999: 112) describe el prestigio que reviste en las ex-colonias africanas la ortografía y no sólo la lengua, de los colonos, en especial en aquellos países que carecían de escritura propia.

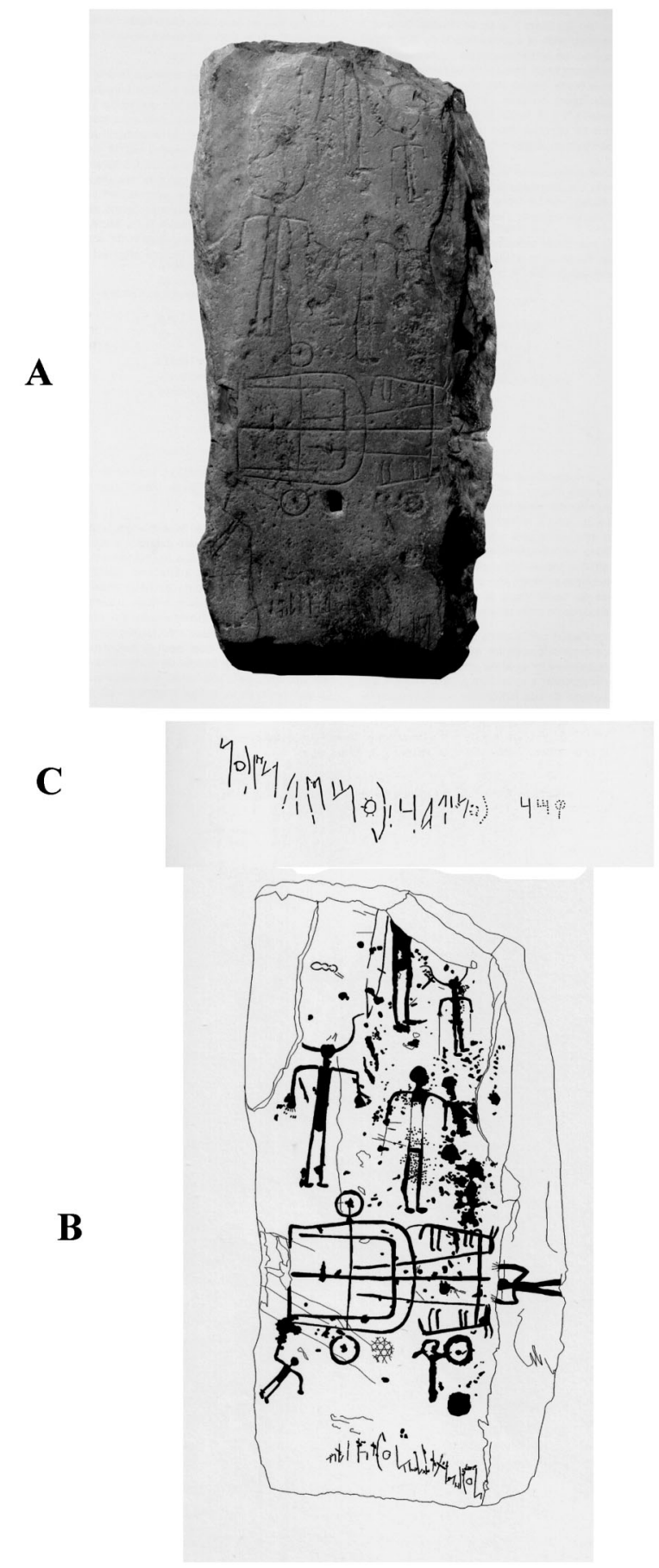

Lám. III. A y B foto y calco de la estela de Majada Honda (Cabezo de Buey, Badajoz). C Calco de la inscripción en escritura del Suroeste (según Domínguez de la Concha et al. 2005).

Aceptar que algunos indígenas, por motivos de prestigio, habrían adoptado la escritura en esos 
momentos anteriores al establecimiento de las colonias fenicias me permitiría entender mejor dos cosas. Primero por qué inmediatamente después, se produce la implantación de emporios fenicios en territorio tartéssico -por ejemplo, Doña Blanca, Carambolo, Coria o Huelva- sin que aparentemente encuentren oposición de sus dirigentes, al contrario de lo que ocurre en Italia, donde los griegos tienen que comerciar con los etruscos desde Pitecoussa y Cumas hasta el siglo VI a.C. en que aquellos les permiten por fin asentarse en Pirgi, el puerto de Cerveteri (Coldstream 1994: 144). Segundo, por qué nos encontramos estelas de guerrero que, como el reciente hallazgo de Majada Honda (Cabezo de Buey, Badajoz) (Domínguez de la Concha et al. 2005: 52-54), la de Capote (Badajoz), Gomes Aires (Baixo Alentejo) y otras (Berrocal 1986; Galán 1993, 2007; Celestino 2001), combinan una típica representación del Bronce Final con una inscripción en grafía del Suroeste. Pues me reafirmo en la idea de la coetaneidad de una y otra ya que, cuando se grabó la inscripción, era evidente que la estela era aún visible, pues de lo contrario ni se hubiera podido escribir, ni hubiera tenido sentido grabar un mensaje que no iba a ser visto. Luego, ambas, la representación del guerrero y la inscripción tuvieron que grabarse en la Edad del Bronce pues, cuando podemos identificar objetos en ellas: espadas, lanzas, escudos, cascos, carros, espejos, liras..., todos ellos corresponden a tipos de la Edad del Bronce que no sobrevivieron en la Primera Edad del Hierro, ni real ni simbólicamente, ya que los emblemas de poder fueron diferentes a partir del período orientalizante. Por ello, a pesar de los intentos de algunos autores por prolongar la cronología de estas estelas hasta el siglo VIII a.C. o incluso más tarde (Moreno Arrastio 2000; Celestino 2001; Aubet 1997 (37); Domínguez de la Concha et al. 2005) o para hacer compatible la presencia de estelas epigráficas en necrópolis del Sudoeste, cuyos materiales se datan en ocasiones en el siglo VII a.C. o incluso i... en el siglo V a.C.

(37) Aubet señala para la de Setefilla un valor funerario que explicaría por qué luego se construye en el mismo lugar un túmulo de la Edad del Hierro. Pero es que Galán y yo jamás hemos negado su significado funerario. Lo que negamos es que se asocien físicamente a tumbas (Ruiz-Gálvez y Galán 1991: 275 punto 5). El caso de las necrópolis del Sudoeste es similar al de Setefilla en el sentido en que donde en la Edad del Bronce había estelas que reclamaban derechos en nombre del antepasado heroico al que la estela conmemoraba, se erige en la Edad del Hierro con la sedentarización del poblamiento, la necrópolis de los descendientes de quienes erigieron las estelas. y en la Segunda Edad del Hierro! (Beirâo 1993; Arruda 2005: 295; Domínguez de la Concha et al. 2005), sigo sosteniendo que estas estelas, o los grafitos grabados en cerámicas de retícula bruñida no pueden tener una fecha posterior al Bronce Final, porque dejaron de existir después; sostengo también que fueron grabados por o para indígenas -quienes o sabían escribir o sabían leer o, plausiblemente, ambas cosas- no por o para comerciantes semitas, pues ambos soportes -estelas cerámica de retícula bruñida- son indígenas y nunca usados por fenicios.

Si la conexión mediterránea fue lo suficientemente sostenida en el tiempo como para que algunos artesanos se asentaran entre indígenas y produjeran cerámicas a torno como las de Gatas o Montoro, o las imitaciones indígenas a mano de cerámicas a torno como las del estrato VI de Montoro y de otros yacimientos del Sudoeste andaluz, y si los indígenas manejaron para comerciar con los mercaderes extranjeros sus mismos sistemas de peso, no me parece descabellado, aunque me consta que a otros muchos sí, plantear que la escritura del Sudoeste, como asimismo la estela de Nora, posean cronología prefenicia. De hecho, en el caso de Italia, donde la arqueología y la arqueometría señalan la introducción de tecnología - know how - como el torno o nuevos cultivos por parte de extranjeros, que tuvieron necesariamente para ello que convivir estrechamente con los indígenas, se ha planteado la influencia del griego micénico en las lenguas itálicas antiguas (Jordán Cólera 1993) (38).

Pero, como decía aquel político, "hoy no toca hablar de ese tema".

\section{BIBLIOGRAFÍA}

Almagro Gorbea, M. 1993: "La introducción del hierro en la Península Ibérica. Contactos precoloniales en el período orientalizante". Complutum 4: 81-94.

Almagro Gorbea, M. y Fontes, F. 1997: "The introduction of wheel-made pottery in the Iberian Peninsula: Mycenaean's or preorientalizing contacts?". Oxford Journal of Archaeology 16(3): 345-361.

Arribas, A. 1976: "Las Bases Actuales para el Estudio del Eneolítico y de la Edad del Bronce en la Penín-

(38) Agradezco muy sinceramente a Javier Celma de la Universidad de Zaragoza, a quien conocí en el coloquio de Córdoba, que me llamara la atención sobre este aspecto y me proporcionara la bibliografía pertinente. También a mis amigos Alfredo González Ruibal y Manuel Domínguez por resolver mis dudas sobre el título en inglés de este artículo. 
sula Ibérica". Cuadernos de Prehistoria de la Universidad de Granada 1: 139-156.

Arruda, A.M. 2005: “Orientalizante e pós-orientalizante no Sudoeste peninsular: geografías e cronologías". En S. Celestino y J. Jiménez (eds.): El período orientalizante. Actas del III Simposio Internacional de Arqueología de Mérida: Protohistoria del Mediterráneo Occidental. Anejos de Archivo Español de Arqueología XXV: 277-303.

Artzy, M. 1994: "Incense, camels and collared jars: desert trade routes and maritime outlets". Oxford Journal of Archaeology 13 (2): 121-47.

Artzy, M. 1997: "Nomads of the sea". En S. Swiny, R.L. Holfender y W. Swiny (eds.): Res Maritimae. Cyprus and the Eastern Mediterranean from Prehistory to Late Antiquity. Scholars Press. Atlanta, Georgia: 1-16.

Artzy, M. 1998: "Routes, trade, boats and nomads of the Sea”. En S. Gitin, A. Mazar y E. Stern (eds.): Mediterranean Peoples in transition. Thirteenth to Early Tenth Centuries BCE. Israel Exploration Society. Jerusalem: 439-448.

Åström, P. 1998: "Continuity or discontinuity: indigenous and foreign elements in Cyprus around 1200 BCE”. En S. Gitin, A. Mazar y E. Stern (eds.): Mediterranean Peoples in transition. Thirteenth to Early Tenth Centuries BCE. Israel Exploration Society. Jerusalem: 80-86.

Åström, P. 1999: "The Cypriot pottery from the Iria Shipreck". En W. Phelps, Y. Lolos e Y. Vichos (eds.): The Point Iria Wreck: Interconnections in the Mediterranean ca. 1200 B.C. Hellenic Institute of Marine Archaeology. Athens: 130-138.

Aubet, M. ${ }^{\text {EE }}$ 1997: "A propósito de una vieja estela". Homenatge a la Pra. Dra. Milagro Gil-Mascarell Boscá. Saguntum 30: 163-72.

Aubet, M. ${ }^{\mathrm{a}} \mathrm{E}$. 2000: "Aspects of Tyrian trade and colonization in the Eastern Mediterranean". Münstersche Beiträge z. antike Handelsgeschicte XIX: 70-101.


del Villar (Málaga)". En M.G. Amadasi-Guzzo, M. Liverani y P. Matthiae (eds.): Da Pirgy a Mozia. Studi sull'Archeologia del Mediterraneo. Vicino Oriente-Quaderni 3/1. Roma: 29-40.

Bass, G. 1967: Cape Gelidonya: A Bronze Age shipwreck. Transactions of the American Philosophical Society 57, 8. Philadelphia.

Bauer, A. 1998: "Cities of the sea: maritime trade and the origins of Philistine settlement in the Early Iron Age Southern Levant". Oxford Journal of Archaeology 17 (2): 149-168.

Beck, P. 1977: “Akko. Tombs near the Persian garden. The cylinder seals". Atiquot 12: 63-69.

Beirâo, C. de M. 1993: "Novos dados arquéologicos sobre a epigrafia da I Idade do Ferro do Sudoeste da Peninsula Ibérica". En J. Untermann y F. Villar (eds.): Actas del V Coloquio sobre Lenguas y Cul- turas Prerromanas en la Península Ibérica (Colonia, 1989). Acta Salmanticensia 251. Salamanca: 683-696.

Belén Deamos, M. 1993: "Mil años de la Historia de Coria: la ciudad prerromana". Azotea. Arqueología de Coria del Río y su entorno: 35-62.

Ben-Arieh, S. y Edelstein, G. 1977: "Akko. Tombs near the Persian garden. The tombs and their contents". Atiquot 12: 1-44.

Bernabeu, J.; Aura, J.E. y Badal, E. 1993: Al oeste del edén: las primeras sociedades agrícolas en la Europa mediterránea. Síntesis. Madrid.

Bernardini, L. 2008: "Dinamiche della precolonizzacione in Sardegna". En S. Celestino, N. Rafel y X.-L. Armada (eds.): Contacto cultural entre el Mediterráneo y el Atlántico (siglos XII-VIII ane). La precolonización a debate. CSIC y Escuela Española de Historia y Arqueología en Roma. Madrid: 161-181.

Bernardini, P. 1991: "Considerazioni sui raporti tra la Sardegna, Cipro e l'area Egeo-Orientale nell'età del Bronzo". Quaderni della Soprintendenza Archeologica per le provincie di Cagliari e Oristano 10.

Bernardini, P. 1993: "La Sardegna e i Fenici. Appunti sulla colonizzazione". Rivista di Studi Fenici 21: 29-81.

Berrocal, L. 1986: "Una nueva aportación al estudio de las estelas y escrituras prerromanas del suroeste peninsular". Boletín de la Asociación de Amigos de la Arqueología 60: 195-207.

Bikai, P. M. 1983: "The imports from the east". En V. Karageorghis (ed.): Palaepaphos-Skales. An Iron Age cemetery of Cyprus. Apéndice II. Universitätszverlag Konstanz. Konstanz: 396-406.

Bronk Ramsey, C. 2000: "Comment on 'The Use of Bayesian Statistics for $14 \mathrm{C}$ dates of chronologically ordered samples: a critical analysis". Radiocarbon 42 (2): 199-202.

Brumfiel, E.M. y Earle, Th.K. 1987: "Specialization, exchange and complex societies: an introduction". En E.M. Brumfiel y Th.K. Earle (eds.): Specialization, exchange and complex societies. Cambridge University Press. Cambridge: 1-9.

Bryce, T.R. 1992: "Lukka revisited". Journal of Near Eastern Studies 51 (2): 121-130.

Cadogan, G. 1998: "The thirteenth-century changes in Cyprus in their East-Mediterranean context". En S. Gitin, A. Mazar y E. Stern (eds.): Mediterranean Peoples in transition. Thirteenth to Early Tenth Centuries BCE. Israel Exploration Society. Jerusalem: 6-16.

Cardona, G.R. 1994: Antropología de la escritura. Gedisa. Barcelona.

Castro, P.; Chapman, R.; Gonzalez, P.; Lull, V.; Micó, R.; Picazo, M.; Risch, R. y Sanahuja, M.E. 1993: "Cuarta campaña de excavaciones en el yacimiento de Gatas (Turre, Almería). Septiembre 1991". Anuario de Arqueología Andaluza 1991, III: 17-23. 
Castro, P.V.; Lull, V. y Micó, R. 1996: Cronología de la Prehistoria Reciente de la Península Ibérica y Baleares (c. 2800-900 cal ANE). British Archaeological Reports (international series) 652. Oxford.

Caubet, A. 2000: "Rash Shamra-Ugarit, before the Sea peoples". En E.D. Oren (ed.): The Sea peoples and their world: a reassessment. The University Museum. Philadelphia: 35-51.

Celestino Pérez, S. 2001: Estelas de guerrero y estelas diademadas. La precolonización y la formación del mundo tartésico. Bellaterra. Barcelona.

Coelho, A. 1986: A Cultura Castreja no Noroeste de Portugal. Museo Arqueológico da Citania de Sanfins. Paços de Ferradeira.

Coldstream, N. 1994: "What sort of Aegean migration?". En V. Karageorghis (ed.): Cyprus in the 11th. century B.C. Leventis Found. Nicosia: 143-6.

Córdoba Alonso, I. y Ruiz Mata, D. 2005: "El asentamiento fenicio arcaico de la calle Cánovas del Castillo (Cádiz). Un análisis preliminar”. En S. Celestino y J. Jiménez (eds.): El período orientalizante. Actas del III Simposio Internacional de Arqueología de Mérida: Protohistoria del Mediterráneo Occidental. Anejos de Archivo Español de Arqueología XXV: 1269-1321.

Cour-Marty, M.-A. 1990: "Les poids égyptiens, de précieux jalons archéologiques". Cahier des Récherches de L'Institut de Papyrologie et d'Egyptologie de Lille 12 (Sociétés urbaines en Égypte et au Soudan). Université de Lille: 17-55.

Courtois, J.C. 1983: "Les poids de Palaepaphos-Skales". En V. Karageorghis (ed.): Palaepaphos-Skales. An Iron Age cemetery of Cyprus. Apéndice VIII: Universitätszverlag Konstanz. Konstanz: 424-425.

Courtois, J.C. 1988: “À propos des archives royales d'Ougarit”. Syria 65: 384-94.

Curtin, Ph. 1984: Cross-cultural trade in World History. Cambridge University Press. Cambridge.

Chandeigne, M. (dir.) 1992: Lisboa extramuros 1415-1580. El descubrimiento del mundo por los navegantes portugueses. Alianza. Madrid.

Chavane, M.J. 1990: "Les pétites objets". En V. Karageorghis (ed.): La nécropole d'Amathonte, tombes 110-385. Service des Antiquites de Chipre et École Française d'Athenes. Nicosia.

Christensen, K. 1998: "Tree-ring Dating of Bronze Age Oak coffins from Denmark". Gods and heroes of the Bronze Age. Europe at the time of Ulysses. National Museum of Denmark/Kunst und Ausstellunghalle der Bundesrepublik Deutschland/Réunion des musées nationaux France/Hellenic Ministry of Culture. Copenhagen, London: 110-113.

Domínguez de la Concha, C.; González Bornay, J.M. y Hoz, J. de. 2005: Catálogo de estelas decoradas del Museo Arqueológico provincial de Badajoz. Siglos VIII-V a.C. Junta de Extremadura. Badajoz.
Doumas, Ch.G. 1998: "Aegeans in the Levant: myth and reality". En S. Gitin, A. Mazar y E. Stern (eds.): Mediterranean Peoples in transition. Thirteenth to Early Tenth Centuries BCE. Israel Exploration Society. Jerusalem: 129-37.

Eiwenger, J. 1989: "Talanton. Ein bronzeeitlicher Goldstandar zwischen Ägais und Mitteleuropa”. Germania 67: 443-462.

Escacena Carrasco, L. 2008: "Cantos de sirena: la precolonización fenicia de Tartessos”. En S. Celestino, N. Rafel y X.-L. Armada (eds.): Contacto cultural entre el Mediterráneo y el Atlántico (siglos XII-VIII ane). La precolonización a Debate. CSIC y Escuela Española de Historia y Arqueología en Roma. Madrid: 301-322.

French, E. 2004. Micenas capital de Agamenón. Bellaterra. Barcelona.

Galán Domingo, E. 1993: Estelas, paisaje y territorio en el Bronce Final del Suroeste de la Península Ibérica. Complutum extra 3. Madrid.

Galán Domingo, E. 2005: “Evolución, adaptación y resistencia. En torno a las formas de intercambio de las comunidades atlánticas en contacto con el mundo orientalizante". En S. Celestino y J. Jiménez (eds.): El período orientalizante. Actas del III Simposio Internacional de Arqueología de Mérida: Protohistoria del Mediterráneo Occidental. Anejos de Archivo Español de Arqueología XXV: 467-475.

Galán Domingo, E. 2007: "De gentiles damas y poderosos guerreros. Trascendiendo el mito de las estelas del Suroeste". En Acercándonos al pasado. Prehistoria en cuatro actos. Ministerio de Cultura y CSIC. Madrid. Edición CD-ROM.

Galán, E. y Ruiz-Gálvez, M. 1996: "Divisa, dinero y moneda. Aproximación a los patrones metrológicos prehistóricos peninsulares". En M. ${ }^{\mathrm{a}} \mathrm{A}$. Querol y T. Chapa (eds.): Homenaje al profesor Manuel Fernández-Miranda. Complutum extra 6. Madrid: 191-215.

Gale, N.H. (ed.) 1991: Bronze Age trade in the Mediterranean. Studies in Mediterranean Archaeology XC, P. Åstroms förlag. Jonsered.

Gillis, C. 1995: "Trade in the Late Bronze Age". En C. Gillis, Ch. Risberg y B.L. Sjöberg (eds.): Trade in premonetary Greece aspects of trade. SIMA pocketbooks 134. Jonsered: 61-86.

Goody, J. 1985: La domesticación del pensamiento salvaje. Akal. Madrid.

Goody, J. 1990: La lógica de la escritura y la organización de la sociedad. Alianza ed. Madrid.

Goody, J. 2003: "Introducción”. En J. Goody (ed.): Cultura escrita en sociedades tradicionales. Gedisa. Barcelona: 11-38.

González de Canales Cerísola, F.; Serrano Pichardo, L. y Llampart Gómez, J. 2004: El emporio precolonial de Huelva (ca. 900-770 a.C.). Biblioteca Nueva. Madrid. 
Green, M.W. 1992: "La escritura cuneiforme temprana”. En W.M. Senner (ed.): Los orígenes de la escritura. Siglo XXI. Méjico: 47-60.

Gregory, C.A. 1982: Gifts and commodities. Academic press. London.

Guerrero, V. 2004: "Las Islas Baleares en los derroteros del Mediterráneo Central y Occidental". En V. Peña, A. Mederos y C.G. Wagner (eds.): La navegación fenicia. Tecnología naval y derroteros. Centro de Estudios Fenicios y Púnicos: 85-133.

Guilaine, J. y Verger, S. 2008: "La Gaule et le Méditerranéen (13-8 siècles avant nôtre ére)". En S. Celestino, N. Rafel y X.-L. Armada (eds.): Contacto cultural entre el Mediterráneo y el Atlántico (siglos XII-VIII ane). La precolonización a debate. CSIC y Escuela Española de Historia y Arqueología en Roma. Madrid: 219-237.

Guy, P.L.O. 1938: Meggido tombs. University of Chicago Press. Illinois.

Hawkins, J.D. 2002: "Anatolia: the end of the Hittite Empire and after". En E.A. Braun-Holzinger y H. Mattäus (eds.): Die nahöstlichen Kulturen un Griecheland an der Wende von 2. zum 1. Jahrtausend v. Chr. Bibliopolid Verlag. Möhnesee: 143-51.

Helck, W. 1987: "The dissolution of the palace economy in the Ramesside period". En R. Hägg y N. Marinatos (eds.): The function of the Minoan palaces. Proceedings of the 4th International Symposium (Athens 1984). Acta Instituti Atheniensis Regni Sueciae, series in 4. ${ }^{\circ}$, XXXII: $17-19$. Stockholm.

Heltzer, M. 1984: "Private property in Ugarit". En A. Archi (ed.): Circulation of goods in non palatial contexts in the Ancient Near East. Ed. de l'Ateneo. ISMEA, C.N.R. Roma.

Hiller, S. 1988: "Dependent personnel in Mycenaean texts". En M. Heltzer y E. Lipinski (eds.): Society and economy in the Eastern Mediterranean (1500-1000 B.C.). Uitgeverj/ Peeters. Lewven: 53-60.

Hoz, J. de 1986: "Escritura fenicia y escrituras hispánicas. Algunos aspectos de su relación". Aula Orientalis 1-2: 73-84.

Hoz, J. de 2005: "La recepción de la escritura en Hispania como fenómeno orientalizante". En S. Celestino y J. Jiménez (eds.): El período orientalizante. Actas del III Simposio Internacional de Arqueología de Mérida: Protohistoria del Mediterráneo Occidental. Anejos de Archivo Español de Arqueología XXV: 363-82.

Jensen, J. 1998: "Oak coffin-graves of the Northen European Bronze Age". Gods and heroes of the Bronze Age. Europe at the time of Ulysses. National Museum of Denmark/Kunst und Ausstellunghalle der Bundesrepublik Deutschland/Réunion des musées nationaux France/Hellenic Ministry of Culture. Copenhagen, London: 108-109.

Jones, R.E. y Vagnetti, L. 1991: "Traders and craftmen in the Central Mediterranean: archaeological evi- dence and Archaeometric Research". En N.H. Gale (ed.): Bronze Age trade in the Mediterranean. Studies in Mediterranean Archaeology XC, P. Åstroms förlag. Jonsered: 127-147.

Jordán Cólera, C. 1993: Nueva revisión y valoración de isófonas e isomorfas compartidas por itálico $y$ griego. Monografías de Lingüística Indoeuropea. Zaragoza.

Kalb, Ph. 1974-1977: "Uma data C-14 para o Bronze Atlântico". O Arqueologo Português 7-9: 141-144.

Karageorghis, V. 1983: Palaepaphos-Skales. An Iron Age cemetery of Cyprus. Universitätszverlag Konstanz. Konstanz.

Karageorghis, V. y Lo Schiavo, F. 1989: “A west mediterranean obelos from Amathus". Rivista di Studi Fenici XVII, 1: 15-29.

Keay, J. 1993: The honourable compagny. A History of the English East India Company. Harper Collins Publishers. London.

Keswani P. 2004: Mortuary ritual and society in Bronze Age Cyprus. Monographs in Mediterranean Archaeology. London.

Killian, K. 1987: “Zur Funktion der mykenischen Residenzen auf dem griechischen Festland". En R. Hägg y N. Marinatos (eds.): The Function of the Minoan Palaces. Proceedings of the $4^{\text {th }}$ International Symposium (Athens 1984). Acta Instituti Atheniensis Regni Sueciae, series in XXXII. Stockholm: 21-28.

Knapp, B. 1998: "Mediterranean Bronze Age trade: Distance, power and place". En E.H. Cline y D. Harris-Cline (eds.): The Aegean and the orient in the Second Millenium. Aegaeum 18. Annales d'Archéologie égéenne de l'Université de Liège and University of Texas at Austin. Liège: 193-207.

Kouru, N. 1994: "Sceptres and maces in Cyprus before, during and inmmediately after the 11th century". En V. Karageorghis (ed.): Cyprus in the 11th century B.C. Leventis Foundation. Nicosia: 203-226.

Larsson, Th.B. 1998: "Symbols in a European Bronze Age Cosmology". En C. Orrling (ed.): Communication in Bronze Age Europe. Transactions of the Bronze Age Symposium in Tanumstrand, Bohusländ, Sweden, 7-5, 1995. The Museum of National Antiquities, Stockholm Studies 9: 9-16. Stockholm.

Liverani, M. 1995: El antiguo Oriente. Historia, sociedad y economía. Crítica. Barcelona.

Liverani, M. 2003: Relaciones internacionales en el Próximo Oriente antiguo. 1660-1100 a.C. Bellaterra. Barcelona.

López Castro, J. L. 2008: “Las relaciones mediterráneas en el II Milenio a.C. y comienzos del I en la Alta Andalucía y el problema de la 'precolonización' fenicia”. En S. Celestino, N. Rafel y X.-L. Armada (eds.): Contacto cultural entre el Mediterráneo y el Atlántico (siglos XII-VIII ane). La 
precolonización a debate. CSIC y Escuela Española de Historia y Arqueología en Roma. Madrid: 273-288.

Macià, M. 2000: El bálsamo de la memoria. Un estudio sobre la comunicación escrita. Visor. Madrid.

Malmer, M. 1992: "Weight systems in the Scandinavian Bronze Age". Antiquity 66: 377-88.

Malmer, M. 1999: "How and why did Greece communicate with Scandinavia in the Bronze Age?". En C. Orrling (ed.): Communication in Bronze Age Europe. Transactions of the Bronze Age Symposium in Tanumstrand, Bohusländ, Sweden, 7-5, 1995. The Museum of National Antiquities, Stockholm Studies 9: 33-42. Stockholm.

Maluquer de Motes, 1958: Excavaciones arqueológicas en el cerro de El Berrueco. Universidad de Salamanca. Salamanca.

Manessy-Guitton, J. 2000: “L' écriture en Grèce avant l'alphabet". En R. Viers (ed.): Des signes pictographiques à l'alphabet. Ed. Karthale. Paris: 213-229.

Manning, S. 1991: The absolute chronology of the Aegean Early Bronze Age; archaeology, radiocarbon and history. Sheffield Academic Press. Sheffield.

Manning, S. 1994: "The emergence of divergence: development and decline on Bronze Age Crete and the Cyclades". En S. Matthers y C. Stoddart (eds.): Development and decline of the Mediterranean Bronze Age. Sheffield Academic Press. Sheffield: 221-70.

Manning, S. y Hulin, S. 2004: "Maritime commerce and geographies of mobility". En E. Blake y B. Knapp (eds.): The Archaeology of Mediterranean Prehistory. Blackwell. Oxford: 270-302.

Manning, S.W.; Kromer, B.; Kuniholm, I. y Newton, M.W. 2001: "Anatolian tree-rings and a new chronology for the East Mediterranean Bronze-Iron Ages". Science 294: 2532-35.

Martín de la Cruz, J.C. 1988: "Mikenische Keramik aus bronzezeitliche Siedlungsschichte as Montoro am Guadalquivir". Madrider Mitteilungen 30: 77-91.

Martín de la Cruz, J.C. 1994: "Los primeros contactos entre Grecia y la Península Ibérica. La problemática planteada por los hallazgos de Montoro (Córdoba)". En D. Vaquerizo Gil (coor.): Arqueología de la Magna Grecia, Sicilia y la Península Ibérica. Actas del encuentro internacional: una aproximación a las relaciones culturales en el marco del Mediterráneo Occidental clásico (Córdoba 1994): 111-46. Córdoba.

Martín de la Cruz, C. 2008: "El Valle medio del Guadalquivir". En S. Celestino, N. Rafel y X.L. Armada (eds.): Contacto cultural entre el Mediterráneo y el Atlántico (siglos XII-VIII ane). La precolonización a debate. CSIC y Escuela Española de Historia y Arqueología en Roma. Madrid: 289-299.

Martín de la Cruz, J.C. y Perlines Benito, M. 1993: "La cerámica a torno de los contextos culturales de finales del segundo milenio a.C. en Andalucía”. Actas do I Congresso de Arqueologia Pe- ninsular. Trabalhos de Antropologia e Etnologia XXXIII. 333-49.

Martín de la Cruz, J.C.; Vera Rodríguez, J.C.; Gavilán Cevallos, B. y Perlines Benito, M. 2005: "Un colgante de cornalina de manufactura oriental procedente de la provincia de Córdoba". En S. Celestino y J. Jiménez (eds.): El período orientalizante. Actas del III Simposio Internacional de Arqueología de Mérida: Protohistoria del Mediterráneo Occidental. Anejos de Archivo Español de Arqueología XXV: 503-9.

Mazar, E. 2004: The Phoenician family tomb n.1 at the Northern cementery of Achziv (10th - 6th centuries BCE: Sam Turner expedition final report of the excavations. Publicaciones del Laboratorio de Arqueología, Universidad Pompeu Fabra de Barcelona. Barcelona.

Mederos, A. 1999: "Ex Occidente Lux. El comercio micénico en el Mediterráneo central y occidental (1625-1100 a.C.)". Complutum 10: 229-66.

Mederos, A. 2002: “Chipriotas o micénicos: Naves y cargamentos mixtos en el Mediterráneo Central (1300-1200 a.C.)". Academia de España en Roma: 85-88.

Melena, J. C. (coord.) 1992. El mundo micénico. Cinco siglos de la primera civilización europea. 1600-1100 a.C. Ministerio de Cultura. Madrid.

Molina, F. 1978: "Definición y sistematización del Bronce Tardío y Final en el sudeste de la Península Ibérica". Cuadernos de Prehisoria de la Universidad de Granada 3: 159-232.

Moreno Arrastio, F. 2000: "Tartessos, estelas, modelos pesimistas". En P. Fernández Uriel, C. González Wagner y F. López Pardo (coord.): Intercambio y comercio preclásico en el Mediterráneo. Centro de Estudios Fenicios y Púnicos. Madrid: 153-74.

Moore Cross, F. 1992: "La invención y el desarrollo del alfabeto". En W.M. Senner (com.): Los orígenes de la escritura. Siglo XXI. Méjico: 76-88.

Naveh, J. 1973: "Some semitic epigraphical considerations on the antiquity of the greek alphabet". American Journal of Archaeology 77: 1-8.

Naveh, J. 1987: Early History of the alpahabet. An introduction to west semitic epigraphy and palaeography. The Magnes Press \& The Hevriew University Jerusalem.

Pacciarelli, M. 1996: "Nota sulla cronologi assoluta dell prima età del ferro in Italia". Ocnus 4: 185-189.

Parise, N. 1970-71: "Per uno studio del sistema ponderale ugarítico". Dialoghi di Archeologia IV-V: 3-36.

Parise, N. 1977: "La documentazione ponderale di Ayia Irini”. En P.E. Pecorella: Le tombe dell'Età del Bronzo Tardo della necropoli a Mare di Agia Irini Paleokastro'. Apendice III. CNR, ISMEA Biblioteca di Antichità Cipriota. Roma: 293-96. 
Parise, N. 1984: "Unità ponderali e rapporti di cambio nella Siria del Nord". En A. Archi (ed.): Circulation of goods in non-palatial context in the Ancient Near East. C.N.R. ed. del'Ateneo. Roma: 125-138.

Parise, N. 1986: "Unità ponderale Egee". En M. Marazzi, S. Tusa y L. Vagnetti (eds.): Traffici micenei nel Mediterraneo. Inst. per la Storia e l'Archeologia della Magna Grecia. Taranto: 303-314.

Pecorella, P.E. 1977: Le tombe dell'Età del Bronzo Tardo della necropoli a Mare di Agia Irini 'Paleokastro'. Cnr Ismea. Biblioteca di Antichità Cipriota. Roma.

Pellicer, M. y Amores, F. 1985: "Protohistoria de Carmona. Los cortes estratigráficos CA-80/A y CA80/B". Noticiario Arqueológico Hispano 22: 55-189.

Perlines Benito, M.R. 2005: 'La presencia de cerámica a torno en contextos anteriores al cambio de milenio. Propuesta de estudio". En S. Celestino y J. Jiménez (eds.): El período orientalizante. Actas del III Simposio Internacional de Arqueología de Mérida: Protohistoria del Mediterráneo Occidental. Anejos de Archivo Español de Arqueología XXV: 477-89.

Peroni, R. 1994: Introduzione alla protostoria italiana. Laterza. Roma-Bari.

Peroni, R. 1998: "Bronzezeitliche Gewichtssysteme in Metalhandel zwischen Mittelmeer und Ostsee". En B. Hänsel (ed.): Mench und Umwelt in der Bronzezeit Europas. Oetker-Voges Verlag. Kiel: 217-224.

Petrie, W.F. 1926: Ancient Weights and Measures. British School of Archaeology 39. London.

Petruso, K. 1978: Systems of weight in the Bronze Age Aegean. Ph. D. dissertation. Indiana University.

Podzuweit, CH. 1990: "Bemerkungen zur mykenischen Keramik von Llanete de los Moros, Montoro, Prov. Córdoba". Praehistorische Zeitschrift 65 (1): 53-8.

Polanyi, K. 1963: "Port of trade in Early societies". Journal of Economic History 23: 30-45.

Popham, M. y Lemos, I. S. 1995: “A Eubean warrior trader". Oxford Journal of Archaeology 14 (1): 151-7.

Pulac, C. 1997: "The Uluburum Shipwreck". En R. Holfelder, S. Swiny y L. Swiny (eds.): Res $M a$ ritimae. Cyprus and the Eastern Mediterranean from Prehistory to Late Antiquity. American Schools of Oriental Research. Archaeological Reports. Atlanta, Georgia: 233-262.

Pulac, C. 2000: "The balance weights from the Late Bronze Age shipwreck at Uluburum". En Ch. Pare (ed.): Metals make the world go round. Oxbow. Oxford: 247-66.

Quilici, L. 1990: La tombe dell'Età del Bronzo Tardo dall'abitato di Paleokastro preso Ayia Irini. Cnr Ismea. Biblioteca di Antichità Cipriota. Roma.

Randsborg, K. 1993: "Kivit. Archaeology and Iconography”. Acta Archaeologica 64 (1): 1-147.

Randsborg, K. 1998: "Kivit powers of communication". En C. Orrling (ed.): Communication in Bron- ze Age Europe. Transactions of the Bronze Age Symposium in Tanumstrand, Bohusländ, Sweden, 7-5, 1995. The Museum of National Antiquities, Stockholm Studies 9: 23-32. Stockholm.

Richardson, S. 1999: "Libya Domestica: Libyan trade and society on the eve of the invasions of Egypt". Journal of American Research Center in Egypt XXXVI: 149-64.

Rodríguez Alcaide, A.; Alonso Jiménez, C. y Velázquez Cano, J. 1996: "La difusión de las especies domésticas: una alternativa a la "ola de avance"". Actas del I Congres del Neolitic a la Peninsula Iberica (Bellaterra, 1995): 835-42.

Rubinos, A. y Ruiz-Gálvez, M. 2003: “El proyecto Pranemuru y la cronología radiocarbónica para la Edad del Bronce en Cerdeña". Trabajos de Prehistoria 60 (2): 91-115.

Ruiz-Gálvez, M. 1993: “El occidente de la Península Ibérica, punto de encuentro entre el Mediterráneo y el Atlántico a fines de la Edad del Bronce". Complutum 4: 41-68.

Ruiz-Gálvez, M. 1995: “Cronología de la Ría de Huelva en el marco del Bronce Final de Europa Occidental". En M. Ruiz-Gálvez (ed.): Ritos de paso y puntos de paso. La ría de Huelva en el mundo del Bronce Final Europeo. Complutum extra 5. Madrid: 79-83.

Ruiz-Gálvez, M. 1998a: La Europa Atlántica en la Edad del Bronce. Un viaje a los orígenes de Europa Occidental. Crítica. Barcelona.

Ruiz-Gálvez, M. 1998b: "Settlement pattern and socio-economic changes in the Bronze Age/Iron Age transition of the Spanish Meseta and Southwest". En B. Hänsel (ed.): Mench und Umwelt in der Bronzezeit Europas. Oetler-Voges Verlag. Kiel: 441-8.

Ruiz-Gálvez, M. 1998c. "Peripheral, but not that much...i". En S. Jorge (ed.): Existe uma Idade do Bronze Atlântico? Instituto Português de Arqueologia y Patrimonio. Lisboa: 101-13.

Ruiz-Gálvez, M. 2000a: "Weight systems and exchange networks in Brone Age Europe". En Ch. Pare (ed.): Metals make the world go round. Oxbow. Oxford: 267-279.

Ruiz-Gálvez, M. 2000b: "La precolonización revisada: De los modelos del s. XIX al concepto de interacción". En P. Fernández Uriel, C. González Wagner y F. López Pardo (coords.): Intercambio y comercio preclásico en el Mediterráneo. Centro de Estudios Fenicios y Púnicos. Madrid: 9-25.

Ruiz-Gálvez, M. 2003: "Investigating weight systems in Nuragic Sardinia”. En F. Lo Schiavo y A. Giumlia-Mair (eds.): The problem of tin at the beginning of metallurgy. British Archaeological Reports, international series 1199. Oxford: 149-157.

Ruiz-Gálvez, M. 2005a: "Der fliegende Mittelmeermann. Piratas y héroes en los albores de la Edad del Hierro". En S. Celestino y J. Jiménez (eds.): El pe- 
ríodo orientalizante. Actas del III Simposio Internacional de Arqueología de Mérida: Protohistoria del Mediterráneo Occidental. Anejos de Archivo Español de Arqueología XXV: 251-275.

Ruiz-Gálvez, M. 2005b: "Representaciones de barcos en el arte rupestre: piratas y comerciantes en el tránsito de la Edad del Bronce a la Edad del Hierro". Mayurga 30, Homenaje a W. Waldren: 307-339.

Ruiz-Gálvez, M. 2008: "Writing, counting, self-awareness, experiencing distant worlds. Identity processes and free-lance trade in the Bronze Age-Iron Age transition". En S. Celestino, N. Rafel y X.-L. Armada (eds.): Contacto cultural entre el Mediterráneo y el Atlántico (siglos XII-VIII ane). La precolonización a debate. CSIC y Escuela Española de Historia y Arqueología en Roma. Madrid: 27-40.

Ruiz-Gálvez, M. y Galán, E. 1991: “Las estelas del Suroeste como hitos de vías ganaderas y rutas comerciales". Trabajos de Prehistoria 48: 257-273.

Schaeffer, C. 1952: Enkomi-Alasia. Librerie C. Klincksieck. Paris.

Schaeffer, C. 1962: Ugaritica IV. Imprimerie Nationale. Paris.

Schmandt-Besserat, D. 1992: "Dos precursores de la escritura: cuentas simples y complejas". En W.M. Senner (ed.): Los orígenes de la escritura. Siglo XXI. Méjico: 34-46.

Schnapp-Goubeillon, A. 2002: Aux origines de la Grèce (XIII-VIII siècles avant notre ère). La génese de la politique. Les Belles Letres. Paris.

Schubart, H. 1976: "Relaciones mediterráneas de la Cultura de El Argar". Zephyrus XXVI-XXVII: 331-42.

Senna-Martínez, J.C. 2000: "O problema dos primeiros ferros peninsulares em contextos do Bronze Final da Orla Atlántica: os dados do 'Outeiro dos castelos de Beijós' (Carregal do Sal)”. Trabalhos de Arqueología da Estudo Arqueológico da Baña do Mondego 6: 43-60.

Senna-Martínez, J.C. 2005: "O outro lado do comércio orientalizante: aspectos da produçâo metalúrgica no pólo indigena. O caso das Beiras portuguesas". En S. Celestino y J. Jiménez (eds.): El período Orientalizante. Actas del III Simposio Internacional de Arqueología de Mérida: Protohistoria del Mediterráneo Occidental. Anejos de Archivo Español de Arqueología XXV: 901-9.

Senner, W.M. 1992: “Teorías y mitos sobre el origen de la escritura: panorama histórico". En W.M. Senner (ed.): Los orígenes de la escritura. Siglo XXI. Méjico: 11-32.

Shelmerdine, C. 1998: "Where do we go from here? and how can the Linear B tablets help us get there?". En E.H. Cline y D. Harris-Cline (eds.): The Aegean and the orient in the Second Millenium. Aegaeum 18. Annales d'Archéologie égéenne de l'Université de Liège \& University of Texas at Austin. Liège: 291-299.
Sherratt, A. 1993: "What Would a Bronze-Age World System Look Like? Relations Between Temperate Europe and the Mediterranean in Later Prehistory". Journal of European Archaeology 1 (2):1-57.

Sherratt, S. 1998: "Sea Peoples and the economic structure of the late Second Millennium in the Eastern Mediterranean". En S. Gitin, A. Mazar y E. Stern (eds.): Mediterranean Peoples in transition. Thirteenth to Early Tenth Centuries BCE. Israel Exploration Society. Jerusalem: 292-311.

Sherratt, S. 2000: "Circulation of metals and the end of the Bronze Age in the Eastern Mediterranean". En Ch. Pare (ed.): Metals make the world go round. Oxbow. Oxford: 82-98.

Sherratt, S. 2001: "Potemkin palaces and route-based economies". En S. Voutsaki y J. Killen (eds.): Economy and politics in the Micenaean palace states. Cambridge Philological Society Supplementary 27. Cambridge: 214-254.

Singer, I. 2000: "New evidence on the end of the Hittite Empire". En E.D. Oren (ed.): The Sea peoples and their world: a reassessment. The University Museum. Philadelphia: 21-28.

Smith, J. 2003: "Writing syles in clay of the Eastern Mediterranean Late Bronze Age". En N.Chr. Stampolidis y V. Karageorghis (eds.): Sea routes... interconnections in the Mediterranean 16th-6th BC. University of Crete and the A.G. Leventis Foundation. Athens: 277-289.

Snape, S.R. 2003: "Zawiye Umm el-Rakham and Egyptian foreing trade in the 13th century BC". En N.Chr. Stampolidis y V. Karageorghis (eds.): Sea Routes...Interconnections in the Mediterranean 16th-6th BC. University of Crete \& A.G. Leventis Foundation. Athens: 63-70.

Snodgrass, A. 2002: "The rejection of Mycenaean culture and the Oriental connection". En E. A. BraunHolzinger y H. Matthäus (eds.): Die nahöstlichen Kulturen und Griecheland an der Wende von 2. zum 1. Jahrtausend v. Chr. Bibiliopolis Verlag. Möhnesee: 1-9.

Stein, G.J. 2005: The Archaeology of colonial encounters. School of American Research Advanced Seminar Series. Houston, Texas.

Stroud, R.S. 1992: "El arte de escribir en la Grecia antigua”. En W.M. Senner (ed.): Los orígenes de la escritura. Siglo XXI. Méjico: 99-113.

Stuiver, M.; Reimer, P.J.; Bard, E.; Beck, J.W.; Burr, G.S.; Hughen, K.A.; Kromer, B.; McCormac, G.; van der Plicht, J. y Spurk, M. 1998: "IntCa198 radiocarbon age calibration, 24,000-0 cal BP'. $R a-$ diocarbon 40 (3): 1041-1083.

Symington, D. 1991: "Late Bronze Age writing boards and their uses: textual evidence from Anatolia and Syria”. Anatolian Studies XLI: 111-124.

Tainter, J. A. 1990: "The collapse of complex societies”. Cambridge University Press. Cambridge. 
Torres Ortiz, M. 2004: "Un fragmento de vaso askoide nurágico del fondo de cabaña del Carambolo". Complutum 15: 45-50.

Torres Ortiz, M. 2008: 'Los 'tiempos' de la precolonización”. En S. Celestino, N. Rafel y X.-L. Armada (eds.): Contacto cultural entre el Mediterráneo y el Atlántico (siglos XII-VIII ane). La precolonización a debate. C.S.I.C. y Escuela Española de Historia y Arqueología en Roma. Madrid: 58-67.

Torres, M.; Ruiz-Gálvez, M. y Rubinos, A. 2005: "La cronología de la cultura nurágica y los inicios de la Edad del Hierro y de las colonizaciones en el Mediterráneo Centro-Occidental. Una aproximación desde la cronología radiocarbónica y el registro arqueológico". En M. Ruiz-Gálvez (ed.): Territorio nurágico y paisaje antiguo. La meseta de Pranemuru en la Edad del Bronce. Anejos de Complutum 10: 169-194.

Tsountas, CH. y Manatt, J.I. 1897: The Mycenaean Age. A study of the monuments and culture of Pre-homeric Greece. MacMillan \& Co. London.

Uriol y Salcedo, J.I. 1990: Historia de los caminos de España. 1. Hasta el s. XIX. Publicaciones del Colegio de Ingenieros de Caminos, Canales y Puertos. Madrid.

Uchitel, A. 1988: "The archives of Mycenaean Greece and the Ancient Near East". En M. Heltzer y E. Lipiòski (eds.): Society and economy in eastern Mediterranean (c. 1500-1000 B.C.). Uitgeverj/Peeters. Lewven: 19-30.

Vagnetti, L. 1993: "Mycenaean pottery in Italy: fifty years of study". En C. Zerner, P. Zerner y J. Winder (eds.): Wace and Blegen. Preceedings of the International Conference. J.C. Gieben publisher. Amsterdem: 143-57.

Vagnetti, L. 1998: "Variety and function of the Aegean derivative pottery in the central Mediterran in the Late Bronze Age". En S. Guitin, A. Mazar y E. Stern (eds.): Mediterranean peoples in transition. Thirteenth to Tenth Centuries BCE. Israel Exploration Society. Jerusalem: 66-79.

Vagnetti, L. 1999: "Mycenaean pottery in the central Mediterranean: imports and local productions in their context". En J.P. Crielaard, V. Stissi y G. van Wijngaarden (eds.): The complex past of pottery production, circulation and consumption of Mycenaean and Greek pottery (sixteenth to early fith centuries B.C.). J.C. Gieber publisher. Amsterdam: 137-146.

Vagnetti, L. 2000: "Western Mediterranean overview: Peninsular Italy, Sicily and Sardinia at the time of the Sea peoples". En E.D. Oren (ed.): The Sea peoples and their world: a reassessment. The University Museum. Philadelphia: 305-326.

Vagnetti, L. y Jones, R.E. 1988: "Towards the identification of local Mycenaean pottery in Italy". En E.B.
French y K.A. Wardle (eds.): Problems in Greek Prehistory. Papers presented at the Centenary Conference of the British School of Archaeology at Athens. Bristol University Press. Bristol: 335-48.

Vichos, Y. y Lolos, Y. 1997: "The Cypro-Mycenaean wreck at Point Iria in the Argolic Gulf: First Thoughts on the origin and Nature of the vessel". En S. Swiny, R.L. Hohlfelfer y H.W. Swiny (eds.): Res Maritimae. Cyprus and the Eastern Mediterranean from Prehistory to Late Antiquity. American Schools of Oriental Research. Archaeological Reports. Atlanta, Georgia: 321-337.

Vilaça, R. 1995: Aspectos do povoamento da Beira Interior (Centro e Sul) nos finais da Idade do Bron$z e$. Trabalhos de Arqueología 9. Instituto Português do Património Arquitectónico. Lisboa.

Vilaça, R. 2003: “Acerca da existência de ponderais em contextos do Brone Final/Ferro Inicial no território português". O Arqueólogo português. Serie IV (21): 245-286.

Vilaça, R. 2006: "Artefactos de ferro em contextos do bronze final do território português: novos contributos e reavaliação dos dados". Complutum 17: 81-101.

Vilaça, R. 2008: "Reflexôes em torno da 'presença mediterranea' no centro do território português, na charneira do Bronze para o Ferro". En S. Celestino, N. Rafel y X.L. Armada (eds.): Contacto cultural entre el Mediterráneo y el Atlántico (siglos XII-VIII ane). La precolonización a debate. CSIC y Escuela Española de Historia y Arqueología en Roma. Madrid: 371-400.

Waschmann, S. 1997: "Were the Sea Peoples Mycenean? The evidence of ship iconography". En S. Swiny, R.L. Hohfelder y H.W. Swiny (eds.): Res Maritimae. Cyprus and the Eastern Mediterranean from Prehistory to Late Antiquity. Scholars Press. Atlanta, Georgia: 339-56.

Waschmann, S. 1998. Seagoing ships and seamanship in the Bronze Age Levant. Texas A\&M University Press.

Yon, M. 1971: Salamine de Chipre II. Le tombe 1 du XIè s. av. J-C. ed. Bocard. Paris.

Yon, M. 2003: "The foreign relations of Ugarit". Sea Routes...Interconnections in the Mediterranean 16th- $6^{\text {th }} B C$. University of Crete \& A.G. Leventis Foundation. Athens: 41-51.

Zaccagnini, C. 1986: "Aspects of copper trade in the Eastern Mediterranean during the Late Bronze Age”. En M. Marazzi, S. Tusa y L. Vagnetti (eds.): Traficci micenei nel Mediterraneo. Istituto per la storia e l'Archeologia della Magna Grecia. Taranto: 413-424.

Zaccagnini, C. 1991: "Nuragic Sardinia: metrological notes". Atti del II Congresso Internazionale di Studi Fenici e Punici. CNR 1: 343-47. Roma. 